
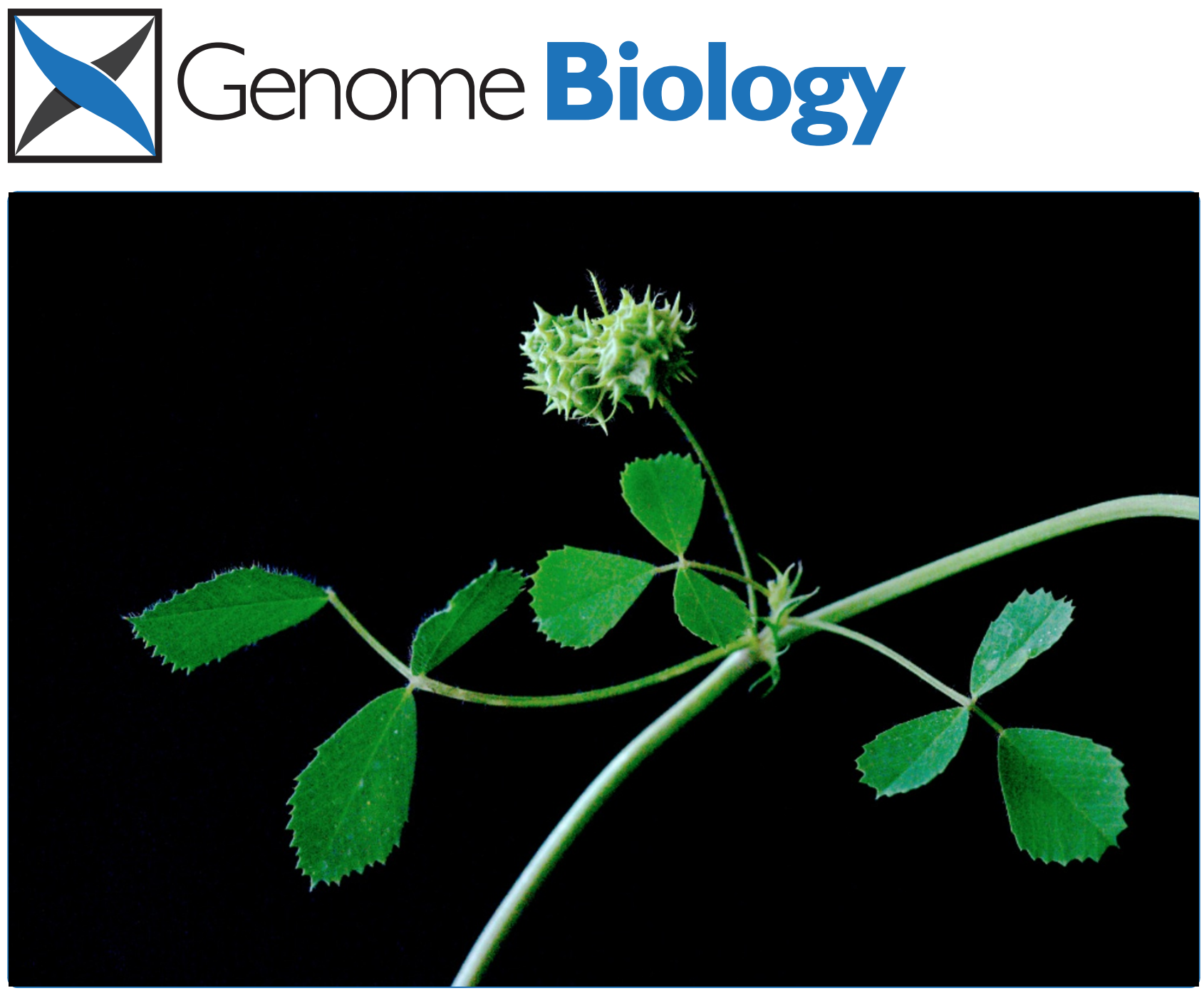

Comparative genomics of the core and accessory genomes of 48 Sinorhizobium strains comprising five genospecies

Sugawara et al.

C Biomed Central 


\title{
Comparative genomics of the core and accessory genomes of 48 Sinorhizobium strains comprising five genospecies
}

\author{
Masayuki Sugawara', Brendan Epstein ${ }^{1,2}$, Brian D Badgley ${ }^{1}$, Tatsuya Unno ${ }^{1}$, Lei Xu', Jennifer Reese ${ }^{1,2}$, \\ Prasad Gyaneshwar ${ }^{3}$, Roxanne Denny ${ }^{2}$, Joann Mudge ${ }^{4}$, Arvind K Bharti ${ }^{4}$, Andrew D Farmer ${ }^{4}$, Gregory D May ${ }^{4}$, \\ Jimmy E Woodward ${ }^{4}$, Claudine Médigue ${ }^{5}$, David Vallenet ${ }^{5}$, Aurélie Lajus ${ }^{5}$, Zoé Rouy ${ }^{5}$, Betsy Martinez-Vaz ${ }^{6}$, \\ Peter Tiffin ${ }^{2}$, Nevin D Young ${ }^{2,7}$ and Michael J Sadowsky ${ }^{1,8^{*}}$
}

\begin{abstract}
Background: The sinorhizobia are amongst the most well studied members of nitrogen-fixing root nodule bacteria and contribute substantial amounts of fixed nitrogen to the biosphere. While the alfalfa symbiont Sinorhizobium meliloti RM 1021 was one of the first rhizobial strains to be completely sequenced, little information is available about the genomes of this large and diverse species group.

Results: Here we report the draft assembly and annotation of 48 strains of Sinorhizobium comprising five genospecies. While S. meliloti and S. medicae are taxonomically related, they displayed different nodulation patterns on diverse Medicago host plants, and have differences in gene content, including those involved in conjugation and organic sulfur utilization. Genes involved in Nod factor and polysaccharide biosynthesis, denitrification and type III, IV, and VI secretion systems also vary within and between species. Symbiotic phenotyping and mutational analyses indicated that some type IV secretion genes are symbiosis-related and involved in nitrogen fixation efficiency. Moreover, there is a correlation between the presence of type IV secretion systems, heme biosynthesis and microaerobic denitrification genes, and symbiotic efficiency.

Conclusions: Our results suggest that each Sinorhizobium strain uses a slightly different strategy to obtain maximum compatibility with a host plant. This large genome data set provides useful information to better understand the functional features of five Sinorhizobium species, especially compatibility in legume-Sinorhizobium interactions. The diversity of genes present in the accessory genomes of members of this genus indicates that each bacterium has adopted slightly different strategies to interact with diverse plant genera and soil environments.
\end{abstract}

\section{Background}

The rhizobia are symbiotic nitrogen-fixing bacteria that form root and/or stem nodules on leguminous plants. Within nodules rhizobia convert atmospheric dinitrogen $\left(\mathrm{N}_{2}\right)$ gas into ammonia, resulting in improved plant growth and productivity, even under N-limiting environmental conditions. These bacteria are among the largest fixers of atmospheric $\mathrm{N}_{2}$ gas in the biosphere and account

\footnotetext{
* Correspondence: sadowsky@umn.edu

'BioTechnology Institute, 1479 Gortner Ave, 140 Gortner Labs, University of Minnesota, St Paul, MN 55108, USA

Full list of author information is available at the end of the article
}

for the deposition of nearly 100 to 195 teragrams per year. The effective use of biological nitrogen fixation via application of rhizobia leads to sustainable cropping systems with a net positive impact on the environment [1]. Most currently recognized legume-nodulating bacteria belong to the $\alpha$-proteobacteria and are members of the genera Allorhizobium, Azorhizobium, Mesorhizobium, Rhizobium, Sinorhizobium (renamed Ensifer), or Bradyrhizobium [2,3]. Recently, some members of the $\beta$ - and $\gamma$-proteobacteria have also been shown to nodulate legume plants [4].

Members of the genus Sinorhizobium are among the most studied and first sequenced rhizobia. Sinorhizobium

\section{Ciomed Central}


meliloti (previously Rhizobium meliloti and now Ensifer meliloti) and its close relative Sinorhizobium medicae induce the formation of root nodules on Medicago species, including Medicago truncatula and Medicago sativa (alfalfa) [5]. In contrast, Sinorhizobium saheli and Sinorhizobium terangae form root and stem nodules with woody leguminous plants, such as Sesbania or Acacia [6], while Sinorhizobium fredii has a very wide host range, nodulating more than 79 plant genera representing all three subfamilies of the family Leguminosae. Although whole genome sequences of some strains of S. meliloti, S. medicae and S. fredii have been published [7-12], and many of their genetic features have been well characterized, only a limited number of strains of each species have been well characterized at the genome level. Recently, Tian et al. [12] reported the comparative genomics of nine strains of $S$. fredii and Baily et al. [13] reported the population genomics of $12 \mathrm{~S}$. medicae strains analyzed using Roche 454 technology. Moreover, only limited comparative genomics studies among each species exist and there are no reports of genomic feature of other species of Sinorhizobium, including the important symbionts of Sesbania/Acacia.

Most rhizobial nodulation genes (nod, noe, and nol) are involved in the synthesis of host-specific lipochitinoligosaccharide (LCO) Nod factors essential for initial infection [14]. Bacterial genes encoding various polysaccharides, cyclic $\beta$-glucans, and type III, IV and VI secretion systems are also involved in symbiosis and host specificity [15-17]. Most of the genes involved in symbiosis are located on large self-transmissible megaplasmids (pSym), or within large genomic symbiotic islands [18]. The megaplasmid pSymA, which has the most symbiosis-related genes in $S$. meliloti, is a more variable replicon than the chromosome or pSymB in this bacterium [10]. Symbiosis-related genes have previously been shown to be highly variable among rhizobial species and strains $[10,19]$ and acquired by via horizontal gene- and plasmid-transfer events. This results in gene replacement and rearrangements leading to genome plasticity [18] and recombination [12] and, ultimately, specificity of symbiotic interactions with their legume hosts. This suggests that gene content in Sinorhizobium strains should vary among strains or species and these alterations could influence their symbiotic phenotype on a host plant. However, few comparative genomic studies have focused on gene content or symbiotic function of multiple strains within or between species of sinorhizobia.

Here we describe the assembly and annotation of the whole genomes of 48 strains of Sinorhizobium described previously [20], with primary focus on S. meliloti and $S$. medicae. While we previously examined 44 of these genomes to characterize population diversity at the single nucleotide level and to determine the forces driving adaptive evolution, our overall goal here was to compare gene content among a large number of strains within a single sinorhizobial species. This was done to better understand functional features in each species and to identify symbiosis-associated genes contributing to symbiotic phenotypes as part of large genome-wide association, SNP, and Hapmap studies [20-22]. Here we show: 1) the genomic features of each Sinorhizobium species; 2) the differences in gene content between $S$. meliloti and the taxonomically and symbiotically related species S. medicae; and 3) the differences among strains and species in genes involved in Nod factor biosynthesis, polysaccharide biosynthesis, protein secretion systems, anaerobic denitrification, and organic sulfur utilization. We also report pair-wise analyses of symbiotic associations of these $46 \mathrm{~S}$. meliloti and $S$. medicae strains with 27 diverse $M$. truncatula genotypes to better understand the relationship of symbiotic phenotype with bacterial genome content.

\section{Results and discussion}

\section{General features of Sinorhizobium genomes}

Annotated draft genome assemblies of 48 Sinorhizobium strains comprising five genospecies - S. meliloti, S. medicae, S. fredii, S. saheli and S. terangae - are presented here (Table S1 in Additional file 1). These assemblies were generated from raw reads used previously to call SNPs in a population genetics analysis [20]. A phylogenetic tree based on 645 protein-coding genes (Figure 1) showed that $S$. meliloti and S. medicae are more closely related to each other than to three other species included in this study. A phylogenetic tree based on the 16S rRNA gene sequence (Figure S1 in Additional file 2) was similar to that shown in Figure 1, but the bootstrap values did not support the nodes to the extent of the tree made from protein coding genes. Genome characteristics are summarized in Table $\mathrm{S} 2$ in Additional file 1. Total genome sizes varied between species and strains and ranged from 6.2 to $7.8 \mathrm{Mb}$. The number of predicted protein coding sequences (CDSs; 6,436 to 8,858 ), and mean mole percentage $\mathrm{G}+\mathrm{C}$ content (61.0 to $63.5 \%)$ also varied among sequenced genomes (Figure 2; Table S2 in Additional file 1). The mean percentage $\mathrm{G}+\mathrm{C}$ content of $S$. meliloti strains $(61.8$ to $62.2 \%$ for all 32 strains) was greater than those seen in S. medicae (60.9 to $61.1 \%$ for all 12 strains) (Figure 2). Genome sizes and CDS counts varied greatly among strains in the same species. While S. meliloti M270 had the largest genome size $(7.8 \mathrm{Mb})$ and number of CDSs $(8,858)$ among all the tested strains, the genome of $S$. saheli USDA 4893 had the smallest genome size (approximately 6.2 Mb) and highest $\mathrm{G}+\mathrm{C}$ content (63.5\%). The genomes of S. fredii and S. terangae were similar to those of S. meliloti or S. medicae, respectively (Figure 2; Table S2 in Additional file 1). Recently, Tian et al. [12] reported a comparative analysis of nine $S$. fredii genomes and found that the average genome size was approximately $6.6 \mathrm{Mb}$, and consisted of a large number of accessory genes likely acquired by 


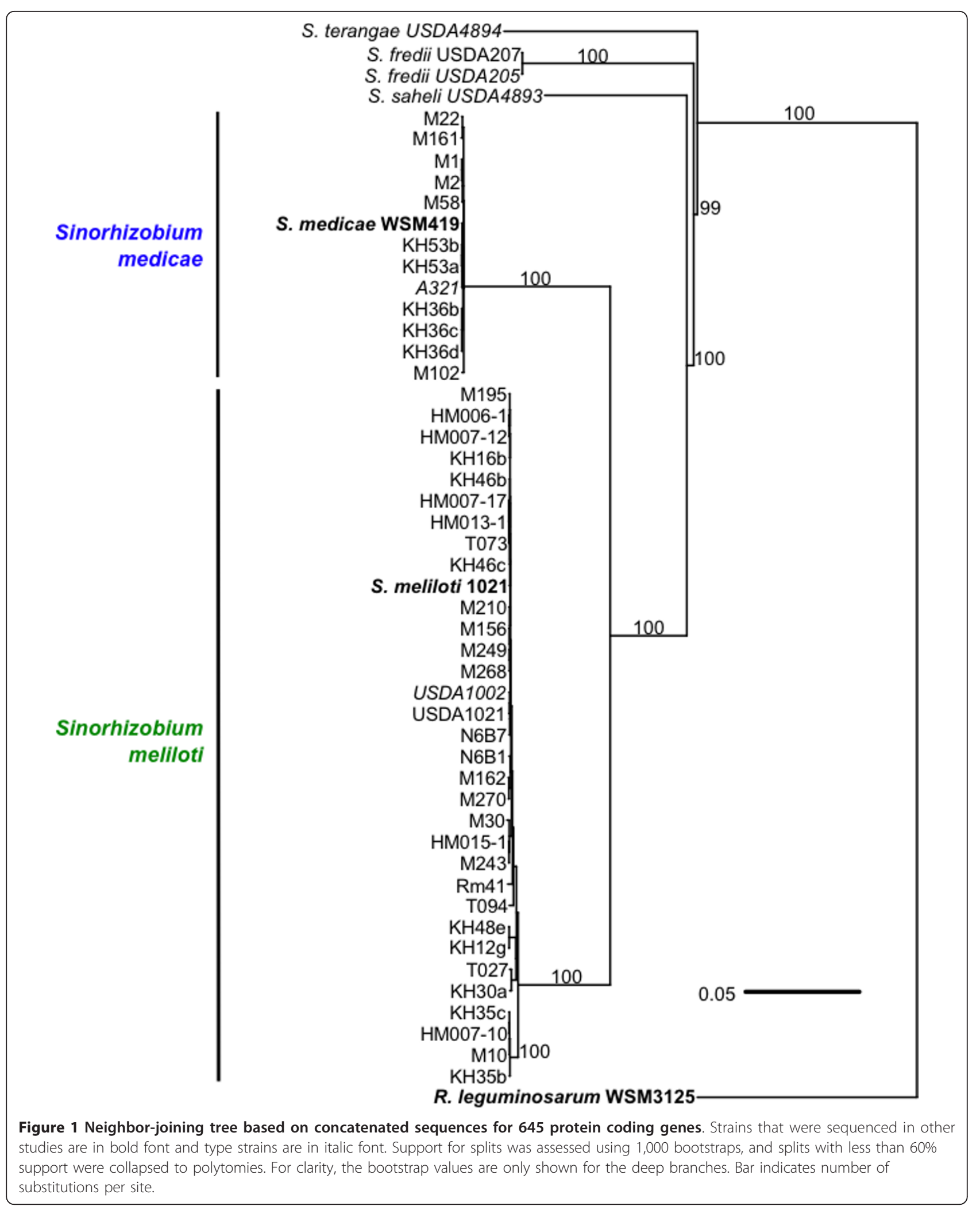




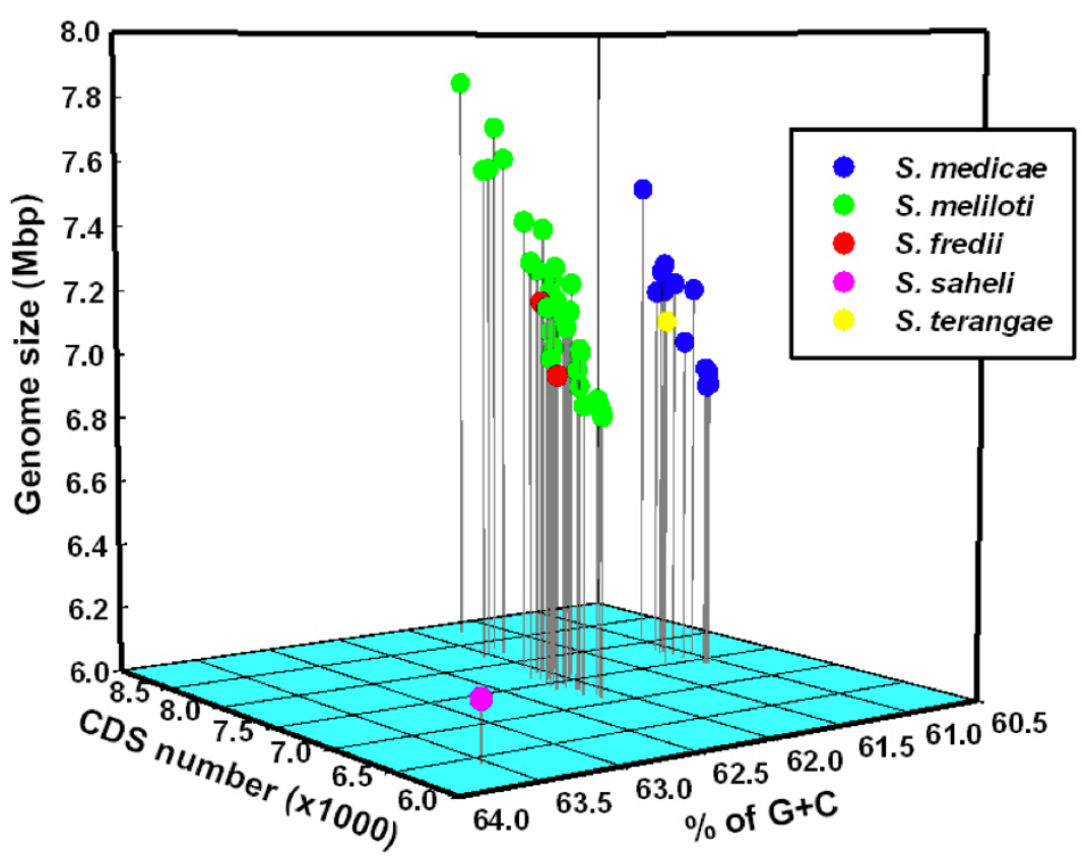

Figure 2 Three-dimensional plots of genome size, coding sequence number and GC content of the 48 Sinorhizobium strains sequenced.

horizontal gene transfer. This is similar to what we report here. All of the strains examined contained from two to five plasmids as determined by Eckhart gel electrophoresis.

\section{Gene contents in Sinorhizobium strains}

To understand the pan-genome of Sinorhizobium more deeply, 380,371 protein CDSs obtained from the 48 newly sequenced genomes plus two reference strains ( $S$. meliloti 1021 and S. medicae WSM419) were clustered using the CD-HIT algorithm with a 70\% sequence identity cut-off. A total of 34,150 clusters were identified, and of these, 2,751 orthologs (8\%) were identified in all 50 strains as the Sinorhizobium core genome (Figure 3a). The remaining variable 31,399 clusters were defined as the Sinorhizobium accessory genome. Species-specific genes were identified among the five tested species (Figure 3a).

Species core orthologous genes and strain-specific unique genes within a given Sinorhizobium species were examined in 33, 13, and 2 strains of S. meliloti, S. medicae, and $S$. fredii, respectively (Figure $3 \mathrm{~b}-\mathrm{d}$ ). In the $S$. meliloti strains, 21,118 orthologous genes were identified from 33 strains, and of these, 4,680 orthologs were present in all tested $S$. meliloti strains as the species core genome (Figure $3 \mathrm{~b}$ ). The number of unique genes in each $S$. meliloti strain varied from 25 to 840 (Figure 3b). S. meliloti strain M270 had the largest genome $(7.8 \mathrm{Mb})$ and the largest number (840) of unique genes. The M270 genome uniquely contained well-correlated regions of the nopaline-type plasmid, pTiC58, found in the plant pathogen
Agrobacterium tumefaciens C58. This included complete sets of trb genes (encoding type IV secretion system proteins involved in conjugal transfer) and nopaline utilization genes (noc).

\section{Functional features of the core and accessory sinorhizobial genomes}

To define possible differences in functions encoded by the core and/or accessory genome in each species group, the proportion of proteins in each COG (Clusters of Orthologous Groups) category was plotted versus COG function. Figure 4 shows that the core-genomes in each Sinorhizobium species group were commonly enriched in COG categories C, F, H, M, J, and V relative to those seen in the accessory genomes. In contrast, accessory genomes were commonly enriched in COG categories Q, $\mathrm{D}, \mathrm{K}$, and $\mathrm{L}$ relative to those of the core genome. There was no major difference in COG category proportion between $S$. meliloti and $S$. medicae, but the abundances of genes in category $\mathrm{G}$ (carbohydrate transport and metabolism) in the accessory genomes were greater in both of these species strains compared to those seen in other sinorhizobia.

Functional differences between S. meliloti and S. medicae While S. meliloti and S. medicae are taxonomically related (Figure 1) with somewhat similar host ranges [5], 421 out of 4,680 S. meliloti core orthlogous genes were not found in the tested 13 strains of S. medicae. Similarly, 


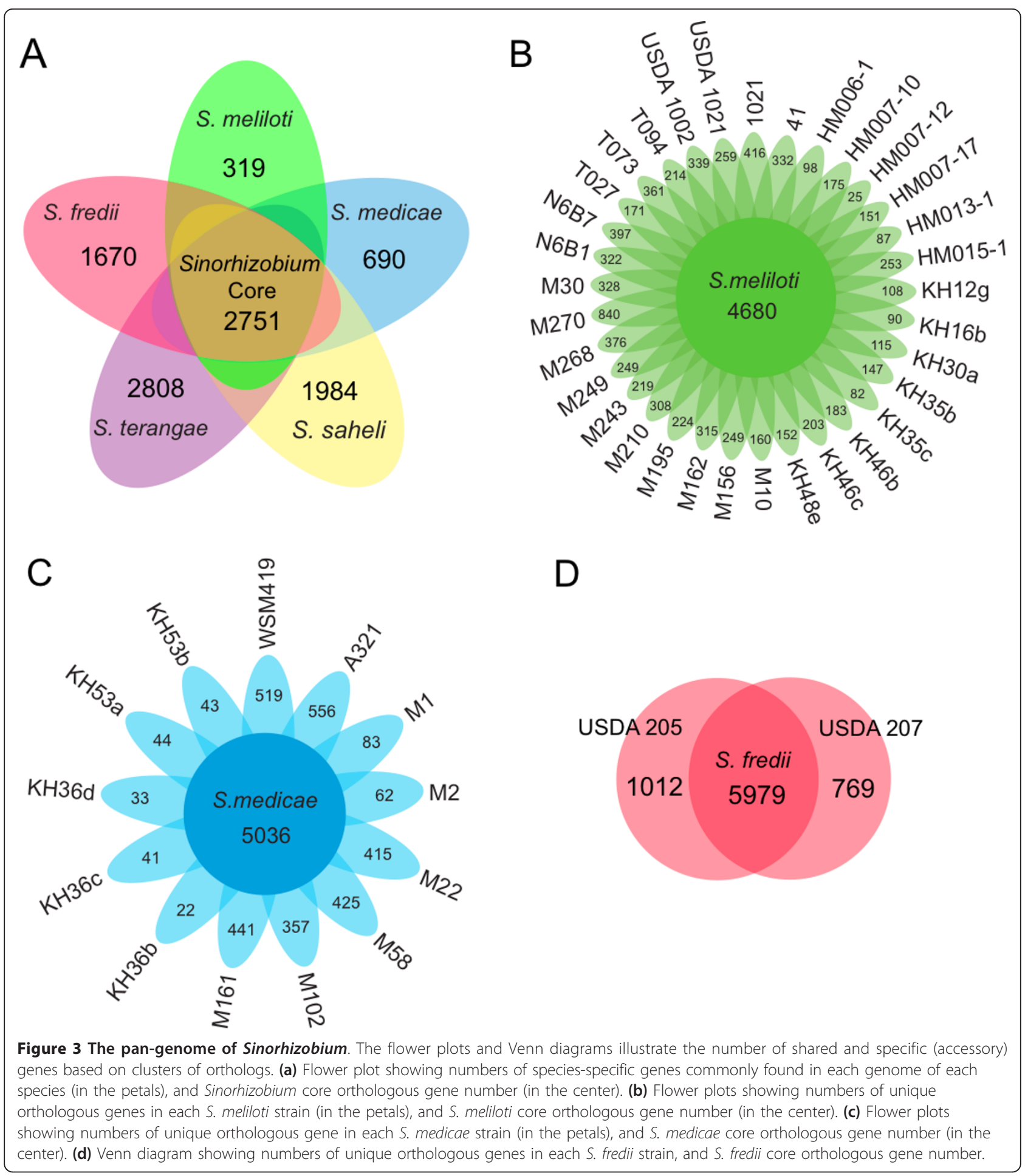

396 out of 5,036 S. medicae core orthologous genes were not found in the 33 tested strains of S. meliloti. Selected S. meliloti- or S. medicae-specific genes in each species are shown in Table 1 and all species-specific genes are presented in Tables S3 and S4 in Additional file 1. These results show that genes involved in conjugation, C1 metabolism, detoxification, and cellular process were specifically identified in the core genomes of each species. In addition, $S$. meliloti specifically possesses genes encoding a nitrate transporter $(n r t A B C)$, a nitrogen regulatory protein $(n t r R)$, and a succinoglycan biosynthetic gene (exoI $\left.I_{1}\right)$. In contrast, $S$. medicae species specifically contain many 


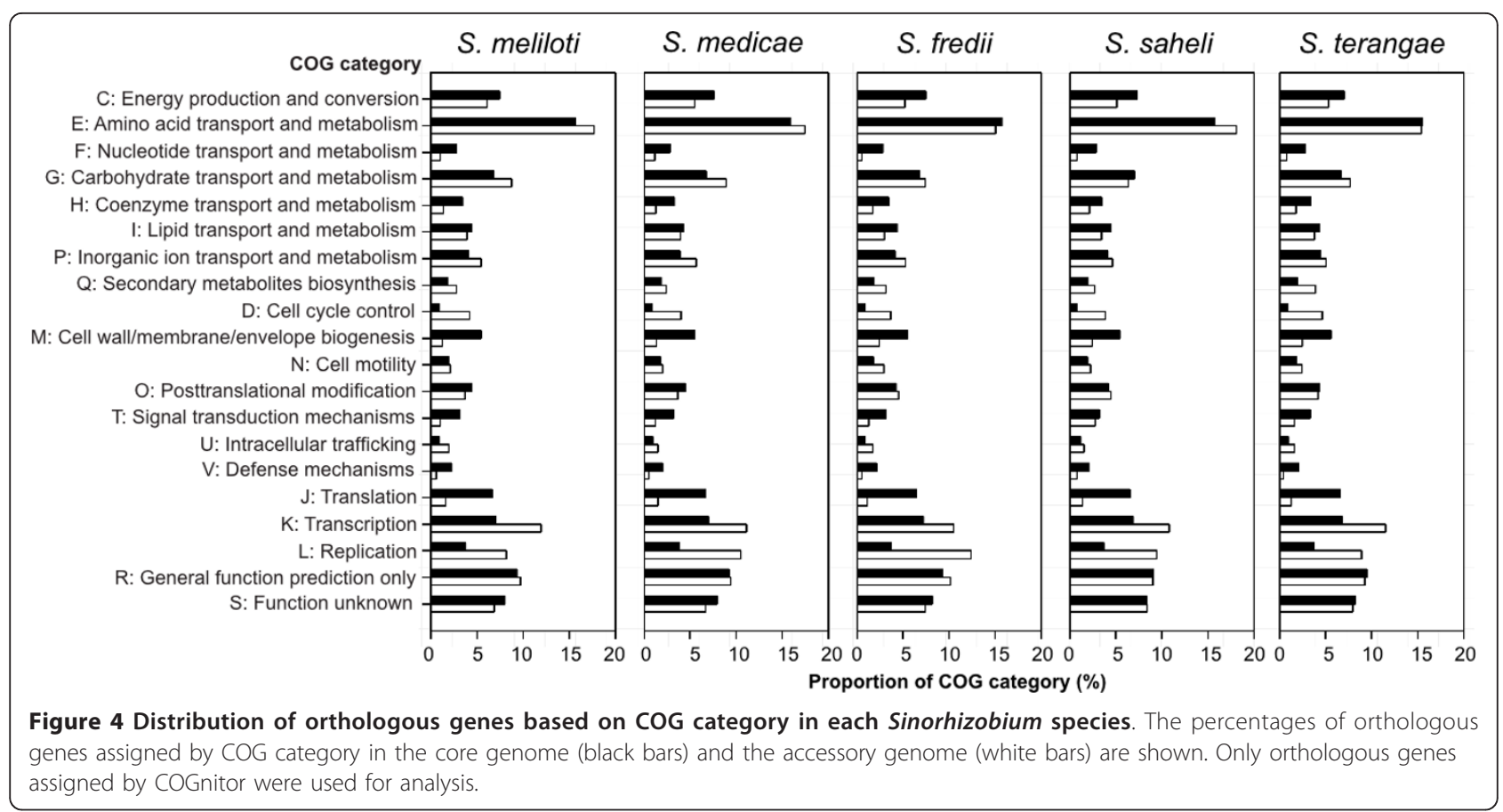

arylsulfatase genes (Figure S2 in Additional file 2) associated with transporter genes. Of particular interest is the prevalence of genes involved in organic sulfur utilization in $S$. medicae, which are also present and expressed in Bradyrhizobium japonicum when in symbiosis with soybean [23]. This is likely to be of functional importance as organic sulfur in the form of sulfur esters and sulfonates constitute approximately $95 \%$ of the total sulfur in aerobic soils [24].

\section{Nod factor biosynthetic genes}

Most nodulation genes (nod, noe, and nol) are involved in the synthesis of host-specific lipo-chito-oligosaccharide (LCOs) Nod factors that are essential for initiation of the symbiosis [14]. Nearly all rhizobia contain the common nod genes [25], which encode Nod factors secreted from rhizobial cells $[14,26]$. Figure 5 shows a physical map of Nod factor biosynthesis genes in all five Sinorhizobium species. The $S$. meliloti and $S$. medicae strains contain a nod $A B C I J$ operon that is closely linked to $\operatorname{nodD}_{1}$ (encoding positive transcriptional regulator of nod genes), whereas nodD $D_{1}$ of S. fredii, S. saheli and S. terangae is not closely linked to the common nod genes. S. meliloti and $S$. medicae had three copies of $\operatorname{nodD}\left(\operatorname{nod} D_{1^{-3}}\right)$ while the other sinorhizobia examined had two copies of nodD. Interestingly, the annotated $\operatorname{nod} N$ (encoding a dehydratase enzyme) was found to be fragmented in many strains of $S$. medicae. The genome of the S. medicae WSM419 contained noe $_{2} \mathrm{~K}_{2}$, whereas $S$. meliloti $\mathrm{KH} 46 \mathrm{~b}$ had two copies of the noeJK genes and a noeLnolK gene cluster involved in the fucosylation of the Nod factors at the C-6 position. Since both WSM419 and KH46b strains did not contain a nodZ homolog, our data suggest that these strains may not fucosylate their Nod factors. In contrast, S. saheli and S. fredii strain USDA 207 possessed a complete set of noeJK-nodZ-noeLK genes. The nod $Z$ in $S$. fredii is also found in B. japonicum and is involved in host-specific nodulation of soybean [27].

The sequenced $S$. saheli and $S$. terangae strains contained the nodSU genes, which are involved in the $N$ methylation and 6-O-carbamoylation of Nod factors [28], inserted between nod $A B C$ and nodIJ genes. In addition, nolO and noeI, which are involved in 3-O-carbamoylation and 2-O-methylation of Nod factors, respectively, were localized downstream of the nodABCIJ cluster in only the genome of $S$. fredii strains. This organization was similar to that reported for the broad host range Rhizobium sp. strain NGR234 [29], but the nolO gene was fragmented in the closely related strains USDA 205 and 207. In contrast, the $S$. meliloti and $S$. medicae strains contained $\operatorname{nod} G P_{1} Q_{1}$, nodM and noeAB, and $S$. saheli had a noeCHOP gene cluster, and only $S$. fredii had a noeI gene.

Strains of $S$. meliloti are known to synthesize sulfated Nod factors via two copies of nodPQ (producing the sulfate donor molecule PAPS) and a nodH sulfotransferase. As PAPS is also a central metabolite for sulfate assimilation, S. meliloti has additional copies of genes for sulfur metabolism and uses nodPQ exclusively for sulfation of Nod factor. In contrast, $S$. saheli and $S$. fredii had only one copy of nodPQ and did not contain nodH, consistent 
Table 1 Selected S. meliloti- or S. medicae-specific genes among both species ${ }^{a}$

\begin{tabular}{|c|c|c|c|}
\hline Species & Gene ID ${ }^{b}$ & Gene name & Function \\
\hline \multicolumn{4}{|c|}{ Conjugation } \\
\hline S. meliloti & SMa0929 & traG & Conjugal transfer coupling protein TraG \\
\hline S. meliloti & SMa0934 & $\operatorname{traA}_{1}$ & Conjugal transfer protein TraA1 \\
\hline S. meliloti & SMa1302 & $\operatorname{vir}_{11}$ & Type IV secretion protein VirB11 \\
\hline S. meliloti & SMa1303 & $\operatorname{vir}_{10}$ & Type IV secretion protein VirB10 \\
\hline S. meliloti & SMa1306 & $\operatorname{vir}_{9}$ & Type IV secretion protein VirB9 \\
\hline S. meliloti & SMa1308 & $\operatorname{vir}_{8}$ & Type IV secretion protein VirB8 \\
\hline S. meliloti & SMa1311 & $\operatorname{virB}_{6}$ & Type IV secretion protein VirB6 \\
\hline S. meliloti & SMa1313 & $\operatorname{vir}_{5}$ & Type IV secretion protein VirB5 \\
\hline S. meliloti & SMa1315 & $\operatorname{virB}_{4}$ & Type IV secretion protein VirB4 \\
\hline S. meliloti & SMa1318 & $\operatorname{virB}_{3}$ & Type IV secretion protein VirB3 \\
\hline S. meliloti & SMa1319 & $\operatorname{virB}_{2}$ & Type IV secretion protein VirB2 \\
\hline S. meliloti & SMa1321 & $\operatorname{vir}_{1}$ & Type IV secretion protein VirB1 \\
\hline S. meliloti & SMa1323 & rctA & Negative transcriptional regulator of vir genes \\
\hline S. medicae & Smed_5050 & $\operatorname{traD}$ & Conjugal transfer TraD family protein \\
\hline S. medicae & Smed_5051 & trac & Conjugal transfer protein TraC \\
\hline S. medicae & Smed_5375 & tral & Acyl-homoserine-lactone synthase \\
\hline S. medicae & Smed_5377 & $\operatorname{trbC}$ & Conjugal transfer protein TrbC \\
\hline S. medicae & Smed_5387 & $\operatorname{traR}$ & Transcriptional activator protein TraR \\
\hline S. medicae & Smed_5388 & $\operatorname{traM}$ & Transcriptional repressor TraM \\
\hline S. medicae & Smed_5391 & $\operatorname{traB}$ & Conjugal transfer protein TraB \\
\hline \multicolumn{4}{|c|}{ Nitrogen metabolism } \\
\hline S. meliloti & SMa0228 & gdhA & Glutamate dehydrogenase \\
\hline S. meliloti & SMa0581 & nrtC & Nitrate transport ATP binding protein \\
\hline S. meliloti & SMa0583 & $n r t B$ & Nitrate $A B C$ transporter permease \\
\hline S. meliloti & SMa0585 & nrtA & Nitrate $A B C$ transporter substrate-binding protein \\
\hline S. meliloti & SMa0981 & $n t r R_{2}$ & NtrR2 transcription regulator \\
\hline S. meliloti & SMc01521 & $n t r R_{1}$ & Nitrogen regulatory protein \\
\hline S. medicae & Smed_1742 & fnrN & Nitrogen fixation regulatory protein \\
\hline \multicolumn{4}{|c|}{ Organic sulfur utilization } \\
\hline S. medicae & Smed_1128 & ssuB-like & Aliphatic sulfonates import ATP-binding protein \\
\hline S. medicae & Smed_1129 & ssuA-like & Aliphatic sulfonates family $A B C$ transporter, periplasmic ligand-binding protein \\
\hline S. medicae & Smed_1130 & atsA-like & Arylsulfatase \\
\hline S. medicae & Smed_3146 & atsA-like & Arylsulfatase \\
\hline S. medicae & Smed_3147 & ssuA & Aliphatic sulfonates family $A B C$ transporter, periplasmic ligand-binding protein \\
\hline S. medicae & Smed_3148 & ssuB & Sulfonate $A B C$ transporter, ATP-binding protein \\
\hline S. medicae & Smed_3150 & ssuC & Alkanesulfonate transport protein; membrane component \\
\hline S. medicae & Smed_3151 & tauC-like & Putative taurine transport system permease protein TauC \\
\hline S. medicae & Smed_2065 & ats $A$ & Arylsulfatase \\
\hline \multicolumn{4}{|c|}{ Detoxification } \\
\hline S. meliloti & SMb21552 & $\mathrm{aacC}_{4}$ & Aminoglycoside $6^{\prime}$-N-acetyltransferase \\
\hline S. meliloti & SMb20505 & $t f x G$ & Trifolitoxin immunity protein \\
\hline S. meliloti & SMc02649 & $\operatorname{ars} C$ & Arsenate reductase protein ArsC \\
\hline S. meliloti & SMc02650 & arsH & Arsenical resistance protein ArsH \\
\hline S. medicae & Smed_0125 & $a a c A$ & Aminoglycoside $N\left(6^{\prime}\right)$-acetyltransferase type 1 \\
\hline S. medicae & Smed_2292 & aphE & Streptomycin 3"-kinase \\
\hline S. medicae & Smed_5053 & arsH & Arsenate resistance protein ArsH \\
\hline S. medicae & Smed_5054 & $\operatorname{ars} B$ & Arsenite resistance protein ArsB \\
\hline S. medicae & Smed_5055 & $\operatorname{ars} C$ & Arsenate reductase \\
\hline \multicolumn{4}{|c|}{ C1 metabolism } \\
\hline S. meliloti & SMa0002 & fdoG & FdoG formate dehydrogenase-O, alpha subunit \\
\hline
\end{tabular}


Table 1 Selected S. meliloti- or S. medicae-specific genes among both species ${ }^{\text {a }}$ (Continued)

\begin{tabular}{|c|c|c|c|}
\hline S. meliloti & SMa0005 & $\mathrm{fdoH}$ & FdoH formate dehydrogenase-O, beta subunit \\
\hline S. meliloti & SMa0007 & fdol & Fdol formate dehydrogenase-O, gamma subunit \\
\hline S. meliloti & SMa0009 & $f d h E$ & Formate dehydrogenase accessory protein FdhE \\
\hline S. meliloti & SMa0011 & selA & L-seryl-tRNA(Sec) selenium transferase \\
\hline S. meliloti & SMa0015 & selB & Selenocysteine-specific elongation factor \\
\hline S. meliloti & SMa0028 & selD & Selenide, water dikinase \\
\hline S. medicae & Smed_2095 & folD & Bi-functional; 5,10-methylene-tetrahydrofolate dehydrogenase and cyclohydrolase \\
\hline S. medicae & Smed_2096 & glyA & Serine hydroxymethyltransferase \\
\hline \multicolumn{4}{|c|}{ Sugars and polysaccharides } \\
\hline S. meliloti & SMb20951 & exol & Succinoglycan biosynthesis protein Exol \\
\hline S. meliloti & SMb21416 & $d d h A$ & Glucose-1-phosphate cytidylyltransferase \\
\hline S. meliloti & $\mathrm{SMb} 21417$ & $d d h B$ & CDP-glucose 4,6-dehydratase \\
\hline S. meliloti & SMb21418 & & NDP-hexose 3-C-methyltransferase \\
\hline S. medicae & Smed_5910 & ots $B$ & Trehalose-phosphate phosphatase \\
\hline \multicolumn{4}{|c|}{ Cellular processes } \\
\hline S. meliloti & SMc03854 & fts $Y$ & Putative cell division protein \\
\hline S. meliloti & SMc03044 & motD & Chemotaxis protein (motility protein D) \\
\hline S. medicae & Smed_1943 & fts $Z$ & Cell division protein FtsZ homolog 2 \\
\hline S. medicae & Smed_0273 & motD & Chemotaxis protein motD \\
\hline \multicolumn{4}{|l|}{ Others } \\
\hline S. meliloti & SMc04203 & fecl & Putative RNA polymerase sigma factor Fecl protein \\
\hline S. meliloti & SMc04204 & fecR & Putative IRON transport regulator transmembrane protein \\
\hline S. meliloti & SMc04205 & & Putative IRON/HEME transport protein \\
\hline S. medicae & Smed_2092 & $d s d A$ & D-serine dehydratase \\
\hline S. medicae & Smed_3282 & $f b p B$ & Ferric transport system permease protein FbpB \\
\hline S. medicae & Smed_3284 & $f b p C$ & Ferric transporter subunit \\
\hline
\end{tabular}

${ }^{a}$ All genes are presented in Tables S3 and S4 in Additional file 1. ${ }^{\mathrm{b}}$ ID of annotated gene in S. meliloti 1021 or S. medicae WSM419.

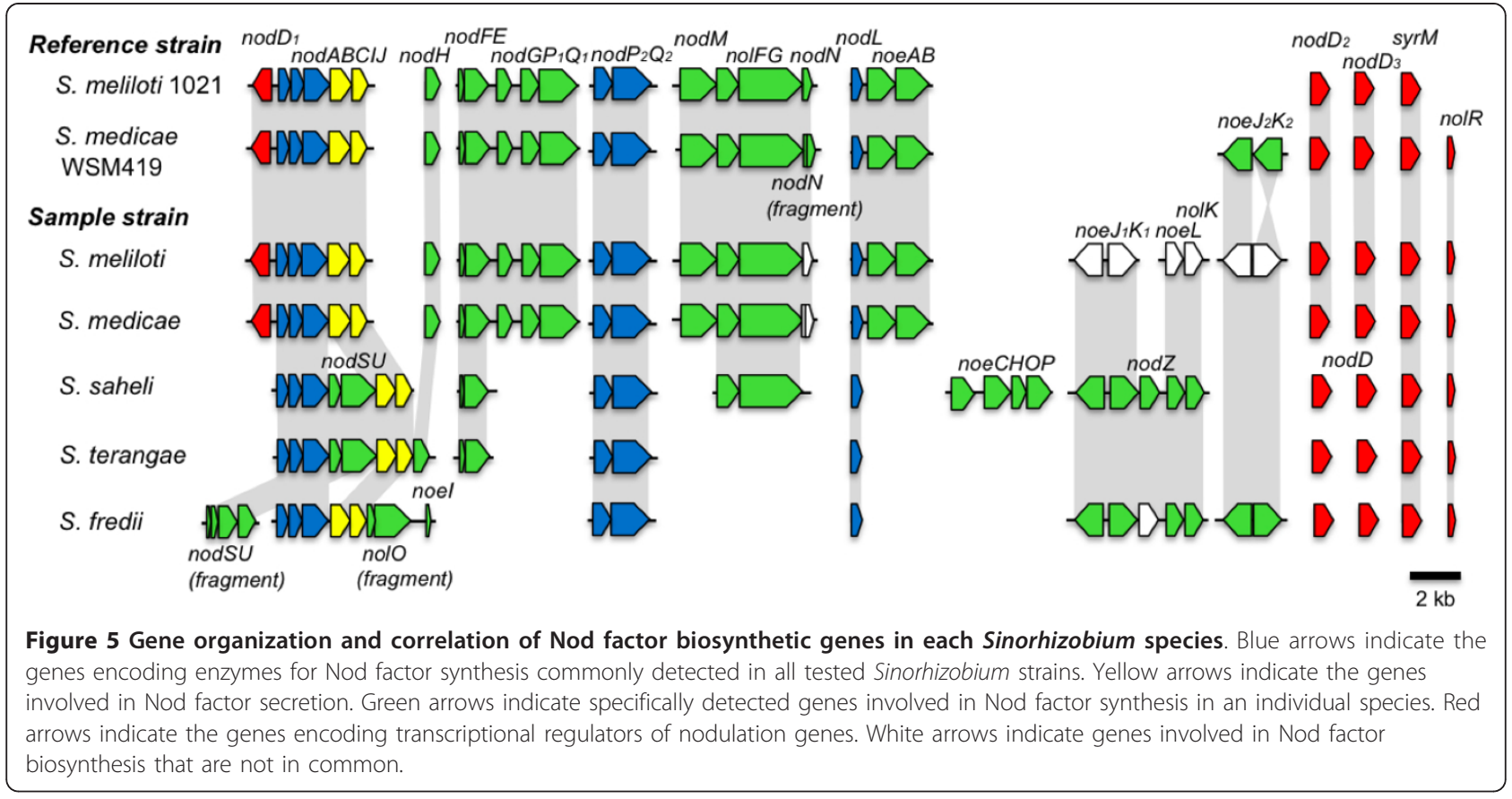


with the Nod factor structure of S. saheli reported earlier [30]. While the Acacia symbiont $S$. terangae strain USDA 4894 had a nodH gene, it contained fewer Nod factor adornment genes than those seen in other species.

The nolR gene, which encodes a negative transcriptional regulator of core Nod factor biosynthesis and is a global regulator in rhizobia [31,32], was detected in all species of Sinorhizobium, although the gene in the reference strain S. meliloti 1021 is not functional [32]. Taken together, these results indicated Nod factor biosynthetic gene content varied among strains of the same species and suggest that LCOs produced by sinorhizobia might be modified in a strain-specific manner. These results are also the first report of genetic organization of nodulation genes in the woody legume symbionts $S$. saheli and $S$. terangae.

\section{Secretion system gene clusters among Sinorhizobium members}

Clusters of genes encoding bacterial type III, IV, and VI protein secretion systems (T3SS, T4SS, and T6SS, respectively) play crucial roles in animal- and plant-bacterial interactions [33]. In rhizobia, these secretion systems are involved in host range determination with their cognate effector proteins modulating host defense reactions [17]. A T3SS gene cluster has been characterized in Rhizobium spp. (S. fredii) NGR234, S. fredii USDA 257 and S. fredii HH103 (USDA 207), and T3SS mutants have symbiotic phenotypes $[34,35]$. However, there are no reports on the roles of T4SS and T6SS systems in sinorhizobial-legume symbioses. Figure 6 shows the structure of the different T3SS, T4SS and T6SS genes found in all the sequenced strains with substantial differences in genomic organization and deduced protein sequences. Notably, the $S$. saheli genome contained T3SS, T4SS, and T6SS gene clusters, as did one of the two $S$. fredii strains, while $S$. medicae strains only contained a T4SS.

Three types of T3SS clusters (types a, b, and c) were identified from several Sinorhizobium strains and all clusters contained the canonical rhcJ-nolUV-rhcNQRST gene cassette (Figure 6a). The T3SSa cluster was detected in nine strains of S. meliloti and S. saheli USDA 4893 and contained $r h c C_{1}, r h c C_{2}, r h c U$, and $r h c V$ (Figure 6b). While most of the genes in the main cluster showed 58 to $94 \%$ protein identity with the corresponding genes in Rhizobium spp. (S. fredii) strain NGR234, gene organization of the flanking regions were different. The T3SSb cluster contained the effector genes (nop) in S. fredii $\mathrm{HH} 103$ strain (USDA 207) and was also identified in S. fredii USDA 205 and S. terangae USDA 4894. Strains having a T3SSc cluster had genes in the main cluster with 40 to $87 \%$ protein identity with those of Rhizobium etli CIAT 652 and were only observed in the genomes of $S$. meliloti M195 and S. terangae USDA 4894. The T3SS types a and c gene clusters found in S. meliloti, S. saheli and S. terangae had a different gene organization from any published

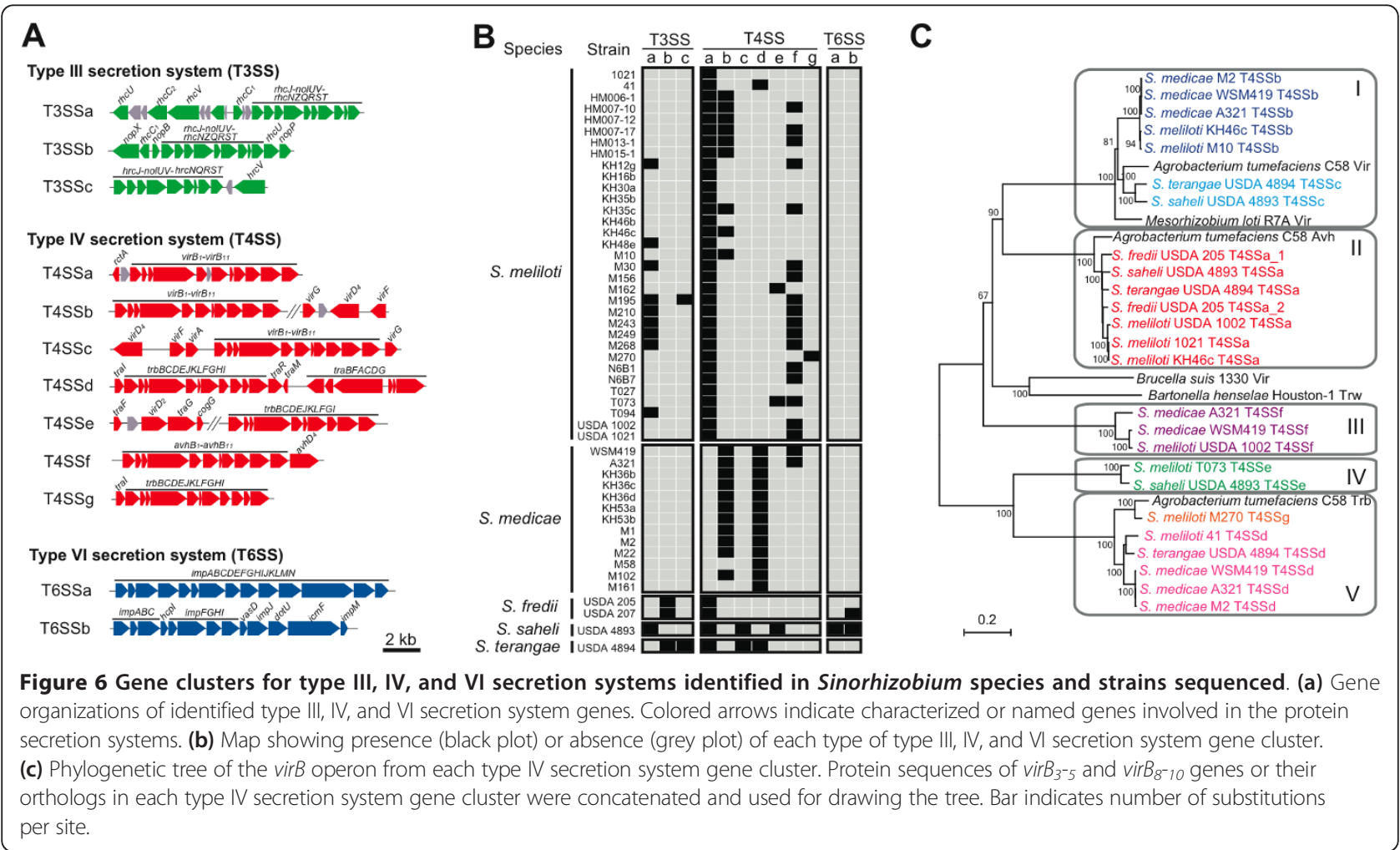


Rhizobium T3SS clusters and did not contain the wellcharacterized nop genes, encoding T3SS-dependent surface appendage or effector proteins. The unique T3SS apparatus found in these strains may encode novel secretion proteins involved in host-specific interactions.

Agrobacterium tumefaciens C58 also uses T4SS for conjugation and DNA transfer [36] and strain C58 possesses three types of T4SS genes: vir, avh, and trb. The virB gene of S. meliloti 1021 (grouped in T4SSa) is involved in conjugation, but is not required for symbiosis with alfalfa [37]. In contrast, vir genes of Mesorhizobium loti strain R7A are involved in protein translocation and have a host-dependent effect on symbiosis [38]. While seven types of T4SS gene clusters (designated T4SSa-g) were identified in the Sinorhizobium genomes (Figure 6a), they were not present in all strains (Figure 6b), suggesting these genes were likely acquired by horizontal gene or plasmid transfer events. To explore the potential function of each Sinorhizobium T4SS gene cluster, a phylogenetic tree was created using selected T4SS protein sequences from diverse bacteria known to infect plant and mammalian hosts (Figure 6c). A total of five clades were detected in the phylogenetic tree and T4SSb and T4SSc were present in clade I, including the Vir proteins of $M$. loti R7A and A. tumefaciens C58. In contrast, proteins in T4SSa, T4SSd, and T4SSg were in clades II or $\mathrm{V}$ and were similar to conjugation transfer proteins Trb or Avh of A. tumefaciens. Since the Sinorhizobium VirB proteins are similar to the symbiotically effective VirB in $M$. loti R7A, these results indicate that the T4SSb and T4SSc genes in Sinorhizobium strains may also influence symbiosis. The T4SSb gene cluster was found in 9 and 11 strains of $S$. meliloti and S. medicae, respectively, and the T4SSc cluster was only found in the Sesbania and Acacia symbionts (S. saheli and S. terangae), suggesting that the cluster plays a role in host-specific interactions.

The T6SS locus (referred to as imp) is a determinant of host specificity in Rhizobium leguminosarum [39]. The S. saheli strain USDA 4893 had two types of T6SS gene clusters, and T6SSb was also present in $S$. fredii USDA 207. The T6SSa cluster is very similar to that seen in $R$. leguminosarum at the amino acid level. No T6SS gene cluster was found in the S. meliloti, S. medicae, and S. terangae strains. Taken together, these results suggest that each sinorhizobial species utilizes different protein secretion strategies to modulate host-specific interactions, although further mutational and functional studies are needed to determine the role of these secretion systems in symbiosis.

\section{General regulatory systems of T3SS and T4SS genes in rhizobia}

In general, the expression of T3SS genes (rhc and nop) or T4SS genes (vir) is induced by the positive regulators TtsI (for T3SS) and VirA (for T4SS). TtsI and VirA bind to a tts- or vir-box in the promoter region of T3SS genes (rhc and nop) and T4SS genes (vir), respectively. In addition, the ttsI and virA genes have a nod box in front of them, indicating that these genes are likely induced by the NodD protein.

The homologous genes of T3SS effector proteins (NopABCJLMPTX from S. fredii NGR234) and the TtsI transcriptional regulator of T3SS genes were searched by BLAST analysis. Results of this analysis indicated that while the nop genes and ttsI were found in the genome of S. fredii USDA 205 and USDA 207 and in S. terangae strain USDA4894, which have the T3SSb gene cluster (Table S5 in Additional file 1), they were not found in the genomes of any S. meliloti strains. Moreover, a canonical nod box consensus sequence was not identified around any region of T3SS-related genes ( $r h c, n o p$ and $t t s I$ ), although tts boxes were found upstream of some nop genes in the genomes of S. fredii USDA205 and USDA207 and the S. terangae strain USDA4894 (Table S6 in Additional file 1), which have the T3SSb cluster.

Blast analyses were used to search the sequenced genomes for genes homologous to those encoding the T4SS effector proteins Msi059 and Msi061 from M. loti R7A and a VirA transcriptional regulator of T4SS genes. While the Msi061 homolog was found in the T4SSb and T4SSc gene clusters, Msi059 was not found in the genomes of any of the Sinorhizobium strains (Table S7 in Additional file 1). A VirA homolog was only found in the genomes of S. saheli strain USDA 4893 and S. terangae strain USDA 4894, in the T4SSc cluster (Table 3). In contrast, nod and vir box-like sequences were not identified in the T4SSb and T4SSc clusters of any of the sequenced strains. Taken together, these results suggest that the expression of identified T3SS and T4SS genes might not be regulated by the previously reported nod box inducers. However, further analysis is needed to examine the regulation of these genes.

\section{Symbiotic phenotypes of T4SSb mutants of S. meliloti and S. medicae}

To further investigate the role of T4SSb in nodulation, deletion mutants of $\operatorname{vir} B_{6}$ to $\operatorname{vir} B_{9}$, predicted to encode essential components of the T4SS apparatus in S. meliloti $\mathrm{KH} 46 \mathrm{c}$ and $S$. medicae M2, were constructed and inoculated onto nine genotypes of $M$. truncatula and one genotype each of M. sativa, Medicago tricycla and Medicago littoralis. A few symbiotic differences between the wildtype strains and the $\mathrm{KH} 46 \mathrm{c}$ and $\mathrm{M} 2 \operatorname{virB}_{6^{-}}$mutants were detected in certain Medicago genotypes (Table 2). M. truncatula cv. A17 and M. tricycla inoculated with the virB $6^{-9}$ mutant of $S$. meliloti KH46c formed significantly fewer nodules and had lower nodule and plant biomass than that seen in plants inoculated with the wild-type strain. Unexpectedly, however, the $\operatorname{virB}_{6^{-9}}$ mutation in S. medicae M2 
Table 2 Symbiotic phenotypes of Medicago plants inoculated with virB mutants of S. meliloti KH46c and S. medicae M2

\begin{tabular}{|c|c|c|c|c|c|c|}
\hline Host plant & Inoculated strain & $\begin{array}{c}\text { Nodule } \\
\text { number }^{\mathrm{a}}\end{array}$ & $\begin{array}{c}\text { Nodule dry mass } \\
(\mathrm{mg})\end{array}$ & $\begin{array}{l}\text { Plant dry mass } \\
(\mathrm{mg})\end{array}$ & $\begin{array}{l}\text { Plant height } \\
(\mathrm{cm})\end{array}$ & $\begin{array}{l}\text { Chlorophyll content } \\
\text { (SPAD unit) }\end{array}$ \\
\hline M. truncatula & KH46c wild-type & 79 & 6.6 & 208 & 12.2 & 44 \\
\hline \multirow[t]{4}{*}{$\mathrm{A} 17$} & $\mathrm{KH} 46 \mathrm{c} \Delta \mathrm{virB}_{6^{-9}}$ & $38^{*}$ & $4.3^{*}$ & $145^{*}$ & $9.5^{*}$ & 43 \\
\hline & M2 wild-type & 102 & 8.4 & 229 & 11.0 & 41 \\
\hline & $\mathrm{M} 2 \Delta \mathrm{vir}_{\sigma^{-9}}$ & 51 & $6.2^{*}$ & 202 & 11.2 & 44 \\
\hline & $\begin{array}{l}\text { Uninoculated } \\
\text { control }\end{array}$ & 0 & 0 & 37 & 3.3 & 17 \\
\hline M. truncatula & KH46c wild-type & 35 & 6.1 & 174 & 10.3 & 42 \\
\hline \multirow[t]{4}{*}{ F83005-5 } & $\mathrm{KH} 46 \mathrm{c} \Delta \mathrm{virB}_{6^{-}} 9$ & 24 & 5.5 & 158 & 9.8 & 39 \\
\hline & M2 wild-type & 29 & 4.9 & 156 & 9.5 & 43 \\
\hline & $M 2 \Delta v_{i r} B_{6^{-9}}$ & 22 & $6.7^{*}$ & $243^{*}$ & $10.7^{*}$ & 41 \\
\hline & $\begin{array}{l}\text { Uninoculated } \\
\text { control }\end{array}$ & 0 & 0 & 44 & 3.3 & 16 \\
\hline M. tricycla & KH46c wild-type & 24 & 12.2 & 315 & 10.5 & 36 \\
\hline \multirow[t]{4}{*}{ R108-C3 } & $\mathrm{KH} 46 \mathrm{c} \Delta \operatorname{vir}_{6^{-}} 9$ & $12^{*}$ & 9.9 & 230 & 10.3 & 34 \\
\hline & M2 wild-type & 11 & 2.8 & 33 & 4.2 & 19 \\
\hline & $\mathrm{M} 2 \Delta \operatorname{vir} B_{6}-9$ & 12 & 3.1 & 33 & 4.2 & 21 \\
\hline & $\begin{array}{l}\text { Uninoculated } \\
\text { control }\end{array}$ & 0 & 0 & 26 & 3.5 & 16 \\
\hline M. satvia cv & KH46c wild-type & 56 & 1.6 & 95 & 8.5 & 54 \\
\hline \multirow[t]{4}{*}{ Agate } & $\mathrm{KH} 46 \mathrm{c} \Delta \mathrm{virB}_{6^{-9}}$ & 42 & $6.8^{*}$ & 55 & 7.2 & $45^{*}$ \\
\hline & M2 wild-type & 31 & 2.5 & 69 & 13.7 & 31 \\
\hline & $\mathrm{M} 2 \Delta \mathrm{vir}_{6^{-} \mathrm{g}}$ & 28 & 2.5 & 85 & 14.6 & $28^{*}$ \\
\hline & $\begin{array}{l}\text { Uninoculated } \\
\text { control }\end{array}$ & 0 & 0 & 79 & 12.5 & 21 \\
\hline
\end{tabular}

${ }^{a}$ Values are per plant. The asterisk indicates a significant difference compared with the wild-type strain by $t$-test $(P<0.05)$ of three biological replicates.

significantly increased nodule and plant biomass on $M$. truncatula cv. F83005-5. The KH46c $\Delta v_{i r B} 6^{-9}$ mutant produced about four-fold greater nodule mass on $M$. sativa cv. Agate than did the wild-type strain (Table 2), but had about three- fold less acetylene reduction activity (432 \pm $376 \mu \mathrm{mol} \mathrm{C}_{2} \mathrm{H}_{4}$ produced/h/g nodule dry weight) than the wild-type $\left(1,132 \pm 163 \mu \mathrm{mol} \mathrm{C}_{2} \mathrm{H}_{4}\right.$ produced/h/g nodule dry weight), suggesting a less effective symbiotic interaction. While further experiments are needed to better understand the function of T4SSb in symbiosis, these results indicate that the T4SSb in Sinorhizobium may indeed play a role in host specificity. Observations from phenotype tests and gene content differences found in the genome data set suggested that the T4SSb secretion system is likely involved in symbiotic nitrogen fixation with specific $M$. truncatula genotypes. In particular, VirB proteins were postulated as symbiotic effector proteins in M. loti R7A [38]. However, we cannot rule out the possibility that other genes are important for host-determination and/or symbiotic efficiency.

\section{Anaerobic denitrification genes}

The ability of rhizobia to denitrify depends on the nap, nir, nor, and nos gene clusters that encode nitrate-, nitrite-, nitric oxide-, and nitrous oxide-reductases, respectively $[40,41]$. Denitrification plays an important role in nitrogen-fixing soybean-Bradyrhizobium japonicum symbiosis and $S$. meliloti has been shown to denitrify under free-living and symbiotic conditions [41]. Genomic data presented here show that while the genomes of S. fredii, S. saheli, and S. terangae strains contained napEFDABC, nirKV, and norECBQD, they did not have the nosRZDFYLX genes that are involved in the terminal step of converting nitrous oxide to $\mathrm{N}_{2}$. In contrast, the nosRZDFYLX gene cluster was identified in 22 S. meliloti strains (Table 3), 19 of which had a complete gene set allowing for the production of $\mathrm{N}_{2}$ gas from nitrate.

\section{Species differences in organic sulfur utilization genes}

The majority of sulfur in agricultural soils is in organic form, such as sulfonates and sulfur-esters [24], and assimilation of these compounds by rhizobia is important for bacterial survival, competition in soils, and during symbiosis [23]. While Koch et al. [42] proposed that sulfonate monooxygenase is involved in host-specific adaptation by B. japonicum, little is known about organic sulfur utilization in sinorhizobia. Genome annotation indicated the presence of organic sulfur utilization genes (Table 3) and likely species-specific differences in the presence of genes for sulfonate monooxygenases 
Table 3 Presence of accessory genes involved in polysaccharide biosynthesis, microaerobic denitrification, lithotrophic growth, and organic sulfur utilization in the genomes of each Sinorhizobium species

\begin{tabular}{|c|c|c|c|c|c|c|}
\hline \multirow[b]{2}{*}{ Gene or gene cluster } & \multirow[b]{2}{*}{ Function } & \multicolumn{5}{|c|}{ Gene present in each Sinorhizobium species ${ }^{a}$} \\
\hline & & $\begin{array}{l}\text { meliloti } \\
(n=33)\end{array}$ & $\begin{array}{l}\text { medicae } \\
(n=13)\end{array}$ & $\begin{array}{c}\text { fredii } \\
(n=2)\end{array}$ & $\begin{array}{l}\text { saheli } \\
(n=1)\end{array}$ & $\begin{array}{c}\text { terangae } \\
(n=1)\end{array}$ \\
\hline \multicolumn{7}{|l|}{ Polysaccharide biosynthesis } \\
\hline $\mathrm{exOF}_{2}$ & Succinoglycan biosynthesis & 7 & 0 & 2 & 0 & 0 \\
\hline exoH & Succinoglycan biosynthesis & 33 & 13 & 0 & 0 & 0 \\
\hline exol & Succinoglycan biosynthesis & 33 & 0 & 0 & 1 & 0 \\
\hline $\mathrm{exO}_{2}$ & Succinoglycan biosynthesis & 11 & 0 & 2 & 0 & 0 \\
\hline $\operatorname{exOP}_{2}$ & Succinoglycan biosynthesis & 7 & 0 & 2 & 0 & 0 \\
\hline exoTWV & Succinoglycan biosynthesis & 33 & 13 & 0 & 0 & 0 \\
\hline $\exp A_{1-10-} \exp G C D_{1} D_{2}-\exp E_{1-8}$ & Galactoglucan biosynthesis & 33 & 13 & 0 & 0 & 1 \\
\hline$r k p-3 ; r k p L M N O P Q$ & $\begin{array}{l}\text { Capsular polysaccharides } \\
\text { biosynthesis }\end{array}$ & 4 & 0 & 2 & 0 & 1 \\
\hline$r k p Z_{1}$ & $\begin{array}{l}\text { Capsular polysaccharides } \\
\text { biosynthesis }\end{array}$ & 33 & 13 & 1 & 1 & 1 \\
\hline$r k p Z_{2}$ & $\begin{array}{l}\text { Capsular polysaccharides } \\
\text { biosynthesis }\end{array}$ & 5 & 0 & 2 & 1 & 1 \\
\hline$r k p T_{2}$ & Surface polysaccharide export & 29 & 13 & 1 & 1 & 1 \\
\hline $\operatorname{cgm} B$ & Cyclic $\beta$-glucan biosynthesis & 1 & 0 & 0 & 0 & 0 \\
\hline \multicolumn{7}{|l|}{ Microaerobic denitrification } \\
\hline napEFDABC & Nitrate reductase & 32 & 13 & 2 & 1 & 1 \\
\hline nirkV & Nitrite reductase & 19 & 9 & 2 & 1 & 1 \\
\hline norECBQD & Nitric oxide reductase & 21 & 9 & 2 & 1 & 1 \\
\hline $\operatorname{nos} R Z D F Y L X$ & Nitrous oxide reductase & 22 & 0 & 0 & 0 & 0 \\
\hline \multicolumn{7}{|l|}{ Lithotroph } \\
\hline $\begin{array}{l}\text { hupSLCDEFGHJKP-hypABFCDE- } \\
\text { hoxX }\end{array}$ & Uptake hydrogenase & 0 & 0 & 0 & 0 & 1 \\
\hline soxYZEF-like & Sulfur oxidation & 7 & 0 & 2 & 0 & 0 \\
\hline soxZ & Sulfur oxidation & 33 & 13 & 2 & 0 & 0 \\
\hline \multicolumn{7}{|l|}{ Organic sulfur utilization $^{\text {b }}$} \\
\hline I: ssuDABCE & Alkanesulfonate degradation & 33 & 13 & 0 & 0 & 1 \\
\hline II: tauRABCXD & Taurine degradation & 33 & 13 & 0 & 0 & 0 \\
\hline III: ssuCBA-atsA-like & Arylsulfatase & 0 & 13 & 0 & 0 & 0 \\
\hline IV: tauC-ssuCBA-ats- like & Arylsulfatase & 0 & 13 & 0 & 0 & 0 \\
\hline V: ssuADCB & Alkanesulfonate degradation & 0 & 0 & 2 & 0 & 0 \\
\hline
\end{tabular}

${ }^{a}$ Values in a column indicate number of strains possessing a gene or gene cluster in a species. ${ }^{\mathrm{b}}$ The genes in each gene cluster are orthologs of Smed_4212-4216 (I), Smed_4858-4863 (II), Smed_1127-1130 (III), Smed_3146-3151 in S. medicae WSM419, and U205v1_247004-247007 (V) in S. fredii USDA 205.

(sulfonate sulfur utilization) or sulfatases (ester-sulfur utilization). S. meliloti and S. medicae specifically had cluster I (ssuDABCE encodes sulfonate transport and desulfonation proteins) and cluster II (tauRABCXD encodes taurine uptake and desulfonation proteins). In contrast, only S. medicae strains contained clusters III and IV, containing arylsulfatases (ester-sulfur utilization) [43] and ssuCBA-like organic sulfur transporter genes (Table 3; Figure S2 in Additional file 2). We tested for sulfatase activity in nodules induced in Medicago genotypes (HM011, HM014, HM019, HM028, HM101) by five S. meliloti (RM1021, M243, M210, M270, M30) and five S. medicae strains (WSM419, M102, M161, A321, M58). With few exceptions, sulfatase activity was greater in nodules induced by $S$. medicae than by $S$. meliloti, averaging 6.1 and 29.4 units/HM011 nodule, respectively. In addition, because $S$. medicae strains commonly have arylsulfatase genes associated with transporter genes (in clusters III and IV), strains of this species may uptake and utilize a wider variety of organosulfur compounds than S. meliloti.

\section{Phenotypic interactions between sequenced} Sinorhizobium spp. strains and diverse $M$. truncatula genotypes

We assessed the symbiotic interaction of $46 \mathrm{~S}$. meliloti or S. medicae strains with $27 \mathrm{M}$. truncatula genotypes. Symbiotic analyses indicated highly significant rhizobial-plant genotype interactions among the tested Sinorhizobium strains and M. truncatula genotypes (Figure 7; Tables S1 


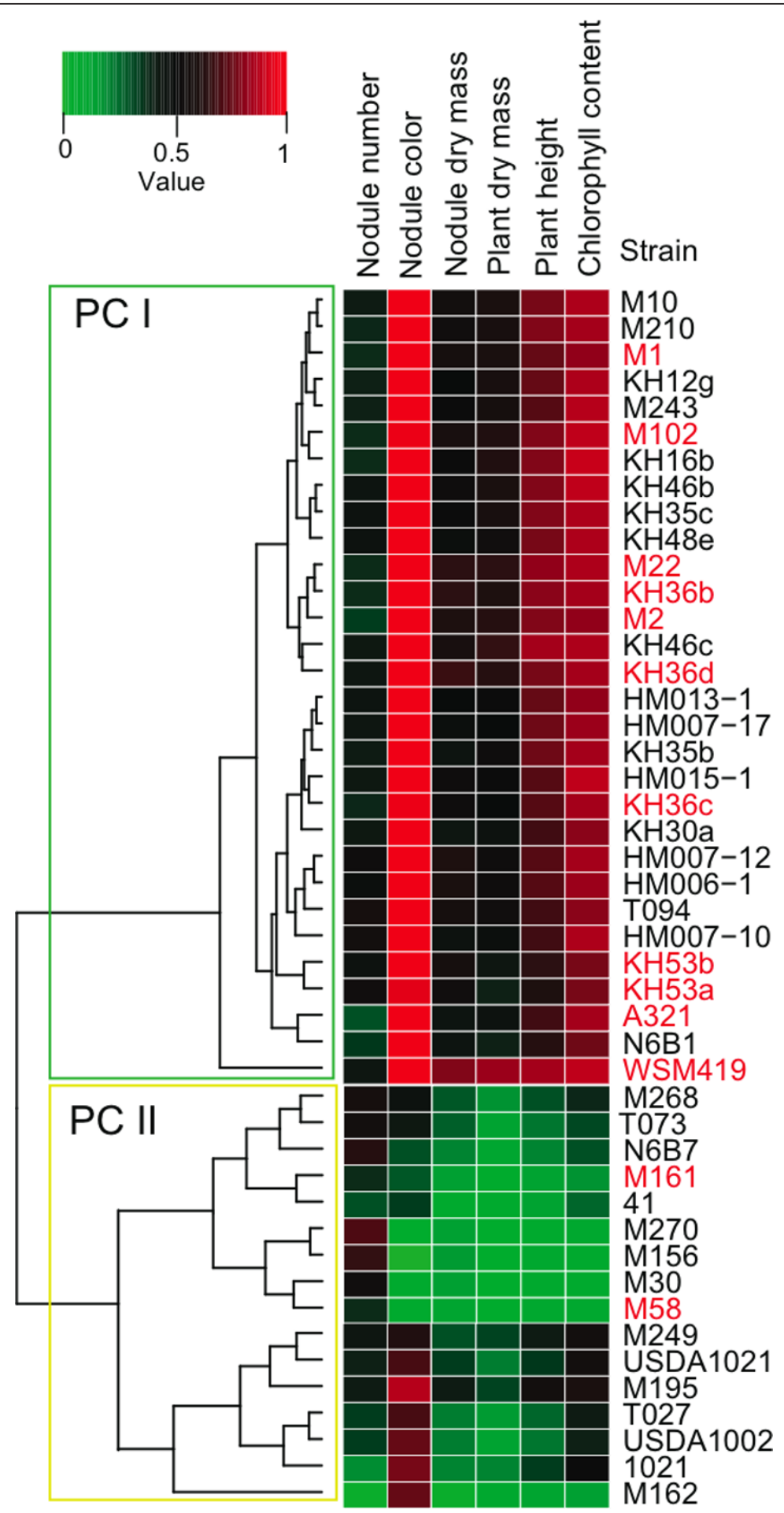

Figure 7 Symbiotic phenotypes of each S. meliloti and S. medicae strain with M. truncatula. Dendrogram and heatmap showing the results of clustering analysis based on the phenotype values. Averaged raw values of each phenotype from three biological replicates were normalized to the range 0 to 1 in each $M$. truncatula genotype. The normalized values were then averaged for 27 genotypes of $M$. truncatula, and clustered. The color in the heatmap indicates the level of value; red indicates the highest and green indicates the lowest value. Black colored names indicate S. meliloti strain, and red colored names indicate S. medicae strain. PC, phenotype cluster. 
and S8 in Additional file 1). Most strains formed nodules on the roots of all $M$. truncatula genotypes, although $S$. meliloti strain M162 did not form nodules on 17 of $27 \mathrm{M}$. truncatula genotypes. The noeA gene, which was characterized as a host-specific nodulation gene [44], was found to be truncated in the nodulation-deficient strain $S$. meliloti M162, suggesting that the failure of this strain to nodulate some Medicago genotypes might be caused by a natural mutation in noeA. A cluster analysis using normalized and averaged values for each phenotype category obtained from all $27 \mathrm{M}$. truncatula genotypes is presented as a heat map (Figure 7). Strains were divided into phenotype clusters I (PC I) and II (PC II). The PC I included 30 strains that showed high compatibility with M. truncatula as measured by the increase in chlorophyll content and plant biomass, significantly more than the 16 strains in the PC II. Strains of both $S$. meliloti and $S$. medicae were present in both PC I and II, suggesting that differences in the symbiotic compatibility with $M$. truncatula were likely caused by strain-specific differences in symbiotic genes.

To investigate the sinorhizobial genes that may affect symbiosis and nitrogen fixation with M. truncatula, we searched previously identified symbiosis-related genes in Sinorhizobium or other rhizobia from the annotated genome data set of $46 \mathrm{~S}$. meliloti or S. medicae strains. The proportion of strains having a full-length gene or gene clusters in each phenotypic cluster were obtained and compared to the proportions in other phenotypic clusters (Table 4). The T4SSb gene cluster (Figure 6) was conserved in $47 \%$ of $S$. meliloti and all $S$. medicae strains grouped in PC I; however, it was absent in all strains grouped in PC II (Table 4). In addition, hemN, involved in heme biosynthesis, and nirK $V$, norECBQD, and nosRZDFYLX, involved in microaerobic denitrification, were also conserved in relatively greater numbers of strains grouped in PC I (Table 4). In contrast, the proportion of strain containing previously reported symbiosis-related genes, such as T3SSa, genes involved in polysaccharide biosynthesis, and acdS (encoding 1-aminocyclopropane-1-carboxylate deaminase), were not differenct between among PC I and PC II strains. Taken together, these results suggest that protein secretion by the newly identified T4SSb and anaerobic respiration by denitrification might have an important role in symbiotic compatibility with $M$. truncatula.

\section{Conclusions}

The results of comparative genomics analysis of the Sinorhizobium genus provide useful information for understanding the genetic functional features of a wide variety of Sinorhizobium species strains, and a tool to better understand incompatibility in legume-rhizobia interactions. The correlation between the presence of T4SS and symbiotic efficiency suggest that each Sinorhizobium strain uses a slightly different strategy to obtain maximum compatibility with a host plant. Moreover, these large genomic data sets provide the opportunity to understand the evolution of rhizobia [20] together with mechanisms of host determination, nodulation, and nitrogen fixation. Our overall goal is to combine these data with our previous studies reporting SNPs in M. truncatula [21] and the sinorhizobia reported here [20] to provide a resource for genome-wide association mapping of genes and traits associated with symbiosis and nodulation. Moreover, the information provided here will be useful to study the population genomics of this bacterium and its evolution with Medicago.

\section{Materials and methods}

\section{Bacteria used in this study}

Illumina GAIIx sequencing was used to sequence the genomes of 32 strains of $S$. meliloti, 12 strains of $S$. medicae, 2 strains of $S$. fredii, and 1 strain each of S. saheli and S. terangae (Table S1 in Additional file 1). The S. meliloti and $S$. medicae strains were chosen from the USDA-ARS Rhizobium Germplasm Collection as representatives of different multi-locus sequence types [45] or obtained from nodules on $M$. truncatula trap hosts inoculated with slurries of soils obtained from several locations in France [46]. Sinorhizobia were also obtained from nodules of seven $M$. truncatula genotypes (HM004, HM006, HM007, HM0013, HM014, HM015 and A17) as trap hosts using Salses soil from France. The type-strains of S. fredii (USDA 205), S. saheli (USDA 4893) and S. terangae (USDA 4894) were chosen from the USDA-ARS Rhizobium Germplasm Collection, and S. fredii USDA 207 (syn. HH103) was also included. The Sinorhizobium strains were grown in TY medium at $30^{\circ} \mathrm{C}$. DNA from each strain was used for Illumina library construction and extracted from culture grown cells using the Wizard Genomic DNA Purification kit (Promega Corp. Madison, WI, USA) with further purification by phenol extraction.

\section{Illumina DNA sequencing}

Paired end libraries were generated using Illumina's Phusion-based library kits following the manufacturer's protocols (Illumina, Hayward, CA, USA). Insert sizes averaged 332 nucleotides (range $=245$ to 443 ). Four samples were multiplexed per lane and sequenced on Illumina GAIIx machines and base-called following the manufacturer's protocols. Sequence reads were paired 90-nucleotide reads. Individual samples averaged just over $1 \mathrm{~Gb}$ of sequence (range of 724 to $1,584 \mathrm{Mb}$ per genome for $S$. meliloti and $S$. medicae strains) translating into an average and minimum coverage of $174 \times$ and $108 \times$, respectively, of the approximately 6.7 Mb genome before aligning reads. Raw reads and derived SNP calls were analyzed previously [20]. 
Table 4 Presence of variable length symbiosis-related genes in each phenotype cluster of S. meliloti and S. medicae

\begin{tabular}{|c|c|c|c|c|}
\hline \multirow[b]{3}{*}{ Gene or gene cluster } & \multicolumn{4}{|c|}{ Species and phenotype cluster $(\mathrm{PC})^{\mathrm{a}}$} \\
\hline & \multicolumn{2}{|c|}{ S. meliloti } & \multicolumn{2}{|c|}{ S. medicae } \\
\hline & I $(n=19)$ & $\|(n=14)$ & $I(n=11)$ & $\|(n=2)$ \\
\hline \multicolumn{5}{|l|}{ Nodulation } \\
\hline $\operatorname{nodN}$ & $95(18)$ & $64(9)$ & 0 & 0 \\
\hline noeA & $100(19)$ & $93(13)$ & $100(11)$ & $100(2)$ \\
\hline noel $_{1} K_{1}$ & $5(1)$ & 0 & 0 & 0 \\
\hline noeJ $_{2} K_{2}$ & 0 & 0 & $9(1)$ & 0 \\
\hline noeLnolK & $5(1)$ & 0 & 0 & 0 \\
\hline \multicolumn{5}{|l|}{ Nitrogen fixation } \\
\hline$f i x Q$ & $100(19)$ & $86(12)$ & $100(11)$ & $100(2)$ \\
\hline fixR & $100(19)$ & $93(13)$ & 0 & 0 \\
\hline$f i x U$ & $95(18)$ & $79(11)$ & $100(11)$ & $100(2)$ \\
\hline nifD & $100(19)$ & $100(14)$ & $100(11)$ & $50(1)$ \\
\hline nifE & $100(19)$ & $100(14)$ & $90(10)$ & $100(2)$ \\
\hline \multicolumn{5}{|l|}{ Succinoglycan (EPS I) biosynthesis } \\
\hline $\mathrm{exOF}_{2}$ & $26(5)$ & $14(2)$ & & \\
\hline exol & $95(18)$ & $100(14)$ & 0 & 0 \\
\hline $\mathrm{exO}_{2}$ & $32(6)$ & $36(5)$ & 0 & 0 \\
\hline exOP 2 & $26(5)$ & $14(2)$ & 0 & 0 \\
\hline exoW & $100(19)$ & $93(13)$ & $100(11)$ & $100(2)$ \\
\hline \multicolumn{5}{|c|}{ Galactoglucan (EPS II) biosynthesis } \\
\hline $\exp D_{2}$ & $95(18)$ & $86(12)$ & $100(11)$ & $100(2)$ \\
\hline $\exp E_{8}$ & $95(18)$ & $100(14)$ & $100(11)$ & $100(2)$ \\
\hline \multicolumn{5}{|l|}{ Cyclic $\beta$-glucan biosynthesis } \\
\hline $\operatorname{cgm} B$ & 0 & $7(1)$ & 0 & 0 \\
\hline \multicolumn{5}{|c|}{ Capusular polysaccharide biosynthesis } \\
\hline$r k p L M N O P Q$ & $16(3)$ & $7(1)$ & 0 & 0 \\
\hline rkpRSTZ & $100(19)$ & $93(13)$ & $100(11)$ & $100(2)$ \\
\hline$r k p T_{2}$ & $84(16)$ & $86(12)$ & $100(11)$ & $100(2)$ \\
\hline$r k p Z_{2}$ & $16(3)$ & $14(2)$ & 0 & 0 \\
\hline \multicolumn{5}{|l|}{ Type III secretion system } \\
\hline T3SSa: rhc, nolUV & $26(5)$ & $29(4)$ & 0 & 0 \\
\hline \multicolumn{5}{|l|}{ Type IV secretion system } \\
\hline T4SSa: rctA, vir & $100(19)$ & $100(14)$ & 0 & 0 \\
\hline T4SSb: vir & $47(9)$ & 0 & $100(11)$ & 0 \\
\hline T4SSd: tra, trb & 0 & $7(1)$ & $100(11)$ & $100(2)$ \\
\hline T4SSe: tra, trb, virD ${ }_{2}, \operatorname{cog} G$ & 0 & $14(2)$ & 0 & 0 \\
\hline T4SSf: avh & $37(7)$ & $71(10)$ & $18(2)$ & 0 \\
\hline T4SSg: tra, trb & 0 & $7(1)$ & 0 & 0 \\
\hline \multicolumn{5}{|l|}{ Denitrification } \\
\hline napEFDABC & $100(19)$ & $93(13)$ & $100(11)$ & $100(2)$ \\
\hline nirkV & $84(16)$ & $29(4)$ & $82(9)$ & 0 \\
\hline norECBQD & $84(16)$ & $29(4)$ & $82(9)$ & 0 \\
\hline nosRZDFYLX & $89(17)$ & $36(5)$ & 0 & \\
\hline \multicolumn{5}{|l|}{ Heme biosynthesis } \\
\hline hemA $A_{2}$ & $16(3)$ & $29(4)$ & 0 & 0 \\
\hline hemN & $74(14)$ & $36(5)$ & $73(8)$ & 0 \\
\hline \multicolumn{5}{|c|}{$\begin{array}{l}\text { 1-Aminocyclopropane-1-carboxylate } \\
\text { deaminase }\end{array}$} \\
\hline acdS (Smed_5532 ortholog) & $21(4)$ & 0 & $36(4)$ & $100(2)$ \\
\hline acdS (Smed_6456 ortholog) & $5(1)$ & $36(5)$ & $36(4)$ & 0 \\
\hline
\end{tabular}

The percentage and number (in parentheses) of strains possessing a gene or gene cluster are shown for each species group and phenotype cluster. 
Sequences were de novo assembled using ABySS [47]. For each strain, several kmers were run and the best resulting assembly was chosen based on assembly contiguity statistics, placement of a subset of high quality read pairs in the assembly with correct spacing, orientation, and comparisons to reference genome sequences.

\section{Automatic gene annotation and clustering CDSs found in the Sinorhizobium genomes}

CDSs were predicted using AMIGene (Annotation of Microbial Genomes) software [48] and predicted genes were functionally annotated as described by Vallenet et al. [49]. More than 20 bioinformatics methods were used for functional and relational analyses: homology search in a generalist databank (UniProt) and in more specialized databases (COG, InterPro, and PRIAM profiles for enzymatic classification), prediction of protein localization using TMHMM, SignalP and PsortB tools, computation of synteny groups with all available complete and incomplete (WGS section at NCBI) proteomes, and metabolic network reconstruction using Pathway Tools [49]. This fully automated first round of annotation ended with a functional assignment procedure to infer specific function(s) for each individual gene. This functional assignment was first based on annotations of the $S$. meliloti 1021 reference genome [50] for strong orthologs ( $>85 \%$ identity over at least $80 \%$ of the length of the smallest protein). All data (syntactic and functional annotations and results of comparative analysis) were stored in the relational database SinorhizoScope. Complete sequence data for the 48 Sinorhizobium genomes are publicly available via the MaGe interface [51]. The SRA sequences have also been deposited under accession SRA048718 and sequences and annotation data have been deposited in GenBank under project number PRJNA172127.

All protein sequences, including automatic and manually annotated CDSs from the 48 sinorhizobial strains and those of reference strains (S. meliloti 1021 and S. medicae WSM419), were clustered by the CD-HIT algorithm [52] using a 70\% cut-off for protein identity. Twenty-eight truncated CDSs in the reference strain genomes and 32 annotated CDSs having less than 11 amino acids identified from all strains were removed from analyses.

\section{Phylogenetic analyses}

Sinorhizobium phylogenetic trees were first created based on 645 concatenated protein-coding sequences; genes were included if they were present in a single copy in all strains and the outgroup (Rhizobium leguminosarum bv. trifolii WSM1325). Homologous sequences were identified in the outgroup by using the MaGe phyloprofile tool to search for bidirectional best hits with at least $70 \%$ protein identity across at least $80 \%$ of the length of both sequences between the outgroup and S. meliloti 1021. A phylogenetic tree was also created based on 16S rRNA gene sequences and alignment to reference genomes in GenBank. Distances between strains were calculated using the dnadist program in phylip [53] v3.69 with the F84 model of evolution, and a neighbor-joining tree was assembled using the neighbor program. Support for the splits in the neighborjoining tree was assessed by constructing neighbor-joining trees on 1,000 bootstrapped datasets created with seqboot, then mapping the support values on to the tree created from the whole dataset using the sumtrees program [54]. The tree was rooted by treating the $R$. leguminosarum strain as an outgroup, and splits with less than $60 \%$ support were collapsed to polytomies.

\section{Sinorhizobium symbiotic phenotype assays}

The Sinorhizobium strains and Medicago genotypes used for phenotype analyses are listed in Table S1 in Additional file 1. Medicago seeds were prepared as described by Bucciarelli et al. [55]. Plant assays were run as a completely randomized block design with three replications in sterile Leonard jar assemblies containing a 1:1 mixture of Sunshine mix \#5 (SunGro Horticulture Inc., Vancouver, Canada) and Turface MVP (Profile Product LLC, IL, USA) and inoculated approximately $10^{7}$ TY-grown Sinorhizobium cells as described previously [56]. Nodulation studies were done at different times, with six plant genotypes tested each time, with one genotype in common. Plants were watered with nitrogen-free plant nutrient solution [55] and incubated in a plant growth chamber at $25^{\circ} \mathrm{C}$ with a 16 -h light condition and at $21^{\circ} \mathrm{C}$ for 8 -h in the dark. Nodule number, color (pink or white), and dry weight, plant dry weight and height, and chlorophyll content of each plant were determined 5 weeks after inoculation. Chlorophyll content in top trifoliate leaves was measured by using a SPAD-502 Chlorophyll Meter (MINOLTA Inc.) and values were averaged. The phenotype data were statistically analyzed by analysis of variance (ANOVA) and Duncan-Waller test using the SAS software package at $\alpha$ $=0.05$. A heatmap was created by using default setting of the 'heatmap.2' program in R 2.14.1 software [57].

\section{Construction of type IV secretion system gene mutants}

S. meliloti strain KH46c and S. medicae strain M2 were selected as recipients for mutation of T4SSb since these strains formed effective nodules on all tested $M$. truncatula genotypes. Mobilizable $v{ }^{2} B_{6^{-}}$inactivation plasmids were constructed as follows. The 2.9-kb $\operatorname{virB}_{6^{-9}}$ coding regions from both Sinorhizobium strains were amplified by PCR using the oligonucleotide primers virB XbaI_F (5'GCTCTAGAAGTCTGGGCTCGTTTCAGA-3') and virB_XbaI_R (5'-CGTCTAGAGCGGACGTCTTGAGGTAGAA-3') containing the newly created XbaI sites 
(underlined). The PCR products were digested by $X b a \mathrm{I}$ and followed by ligation into suicide vector pK18mob to create pMS21 (for KH46c virB) or pMS22 (for M2 virB). These plasmids were digested by $S s p \mathrm{I}$ and $S c a \mathrm{I}$ to delete a $1.6-\mathrm{kb}$ fragment containing the $\operatorname{vir} B_{6}$ to $\operatorname{vir} B_{9}$ coding region, and the $\Omega$ cassette from pHP $45 \Omega$ was inserted to create pMS25 (KH46c virB:: $\Omega$ ), or pMS26 (M2 virB:: $\Omega$ ). The plasmids pMS25 or pMS26 were introduced into $S$. meliloti $\mathrm{KH} 46 \mathrm{c}$ or $S$. medicae M2 by triparental mating. Mutated strains were selected on TY agar plates containing $20 \mu \mathrm{g}$ of chloramphenicol $(\mathrm{Cm})$ per $\mathrm{ml}$ and $100 \mu \mathrm{g}$ of spectinomycin/streptomycin $(\mathrm{Sp} / \mathrm{Sm})$ per $\mathrm{ml}$. Gene replacement, double crossover mutants were verified by their antibiotic resistance phenotype $(\mathrm{Cm}$ and $\mathrm{Sp} / \mathrm{Sm}$ resistant, and neomycin sensitive), and by PCR amplification using primers that spanned the insertion sites.

\section{Acetylene reduction assay}

The nodulated plant roots were removed aseptically with scissors. Detached roots were placed in air-tight $150 \mathrm{ml}$ serum bottles. Three $\mathrm{ml}$ of the air volume in each bottle was replaced by pure acetylene gas (99.8\%) using hypodermic syringes. The bottles were incubated at room temperature for 60 minutes. The ethylene concentration in each bottle, before and after incubation, was analyzed by gas chromatography using a Nucon-5765 gas chromatograph (AIMIL Instruments, New Delhi, India) equipped with a flame ionization detector (FID) and a Rt-Alumina BOND $/ \mathrm{Na}_{2} \mathrm{SO}_{4}$ column $(30 \mathrm{~m} \times 0.53 \mathrm{~mm})$ (Restek Corp., Bellefonte, PA, USA). Nitrogen was used as the carrier gas. The operation temperatures for oven, injector, and detector were set at $50^{\circ} \mathrm{C}, 20^{\circ} \mathrm{C}$ and $104^{\circ} \mathrm{C}$, respectively. All the experiments were conducted in triplicate.

\section{Sulfatase activity test}

Enzyme solutions were prepared by crushing 10 nodules aseptically in $150 \mu \mathrm{l}$ sterilized $0.85 \% \mathrm{NaCl}$ and the mixture was homogenized by votexing for $15 \mathrm{~s}$. Sulfatase assays were done as previously described [58]. The method was modified by using $50 \mathrm{mM}$ phosphate buffer, pH 7.0, instead of 0.5 M Tris acetate buffer, pH 8.75.

\section{Additional material}

Additional file 1: Tables S1 to S8.

Additional file 2: Figure S1 and S2

\section{Authors' contributions}

MS, MJS, NDY, PT and BE wrote the manuscript. MS, BE, LX, JR and RD carried out plant experiments. MS, BE, BB, JM, AKB, ADF, AF, GM and JEW participated in genome sequencing, assembly, and gene annotation. MS, MJS, BE, BB, TU, LX, GP, MJS, CM, DV, AL, ZR, JM, AKB, ADF and BMV carried out analysis of the genome sequences. MJS, NY, PT and BM were the principal investigators (PIs) of this study.

\section{Competing interests}

The authors declare that they have no competing interests.

\section{Acknowledgements}

We would like to thank Joelle Ronfort and Jean-Marie Prosperi for providing M. truncatula seeds and soils, Kais Zribi and Mohammed Aouani for strains, John Ferguson for help with figures, and Emmanuel Mongodin for helpful suggestions. This work was funded by Grant 0820005 from The National Science Foundation.

\section{Author details}

'BioTechnology Institute, 1479 Gortner Ave, 140 Gortner Labs, University of Minnesota, St Paul, MN 55108, USA. ²Department of Plant Biology, 250 Biological Sciences, 1445 Gortner Ave, University of Minnesota, St Paul, MN 55108, USA. ${ }^{3}$ Department of Biological Sciences, 3209 N. Maryland Ave, University of Wisconsin-Milwaukee, Milwaukee, WI 53211, USA. ${ }^{4}$ National Center for Genome Resources, 2935 Rodeo Park Drive East, Santa Fe, NM 87505, USA. ${ }^{5}$ CNRS, UMR8030 \& UEVE, Université d'Evry \& CEA/DSV/IG/ Genoscope, Laboratoire d'Analyses Bioinformatiques pour la Génomique et le Métabolisme, Centre National de Séquençage, 2 rue Gaston Crémieux CP5706 91057, Evry cedex, France. 'Department of Biology, MS-B1807, 1536 Hewitt Avenue, Hamline University, St Paul, MN 55104, USA. ${ }^{7}$ Department of Plant Pathology, 495 Borlaug Hall, 1991 Upper Buford Circle, University of Minnesota, St Paul, MN 55108, USA. ${ }^{8}$ Department of Soil, Water, \& Climate, 491 Borlaug Hall, 1991 Upper Buford Circle, University of Minnesota, St Paul, MN 55108, USA.

Received: 9 October 2012 Revised: 27 January 2013

Accepted: 20 February 2013 Published: 20 February 2013

\section{References}

1. Bohlool BB, Ladha JK, Garrity DP, George T: Biological Nitrogen-Fixation for Sustainable Agriculture - a Perspective. Plant Soil 1992, 141:1-11.

2. Martínez-Romero E, Caballero-Mellado J: Rhizobium phylogenies and bacterial genetic diversity. Crit Rev Plant Sci 1996, 15:113-140.

3. Young JPW, Haukka KE: Diversity and phylogeny of rhizobia. New Phytol 1996, 133:87-94.

4. Gyaneshwar P, Hirsch AM, Moulin L, Chen WM, Elliott GN, Bontemps C, Estrada-de Los Santos P, Gross E, Dos Reis FB, Sprent JI, Young JP, James EK: Legume-nodulating betaproteobacteria: diversity, host range, and future prospects. Mol Plant-Microbe Interact 2011, 24:1276-1288.

5. Rome S, Fernandez MP, Brunel B, Normand P, Cleyet-Marel JC: Sinorhizobium medicae sp. nov., isolated from annual Medicago spp. Int J Syst Bacteriol 1996, 46:972-980.

6. de Lajudie P, Willems A, Pot B, Dewettinck D, Maestrojuan G, Neyra M, Collins MD, Dreyfus B, Kersters K, Gillis M: Polyphasic taxonomy of rhizobia: emendation of the genus Sinorhizobium and description of Sinorhizobium meliloti comb. nov., Sinorhizobium saheli sp. nov., and Sinorhizobium teranga sp. nov. Int J Syst Bacteriol 1994, 44:715-733.

7. Galibert F, Finan TM, Long SR, Puhler A, Abola P, Ampe F, Barloy-Hubler F, Barnett MJ, Becker A, Boistard P, Bothe G, Boutry M, Bowser L, Buhrmester J, Cadieu E, Capela D, Chain P, Cowie A, Davis RW, Dreano S, Federspiel NA, Fisher RF, Gloux S, Godrie T, Goffeau A, Golding B, Gouzy J, Gurjal M, Hernandez-Lucas I, Hong A, et al: The composite genome of the legume symbiont Sinorhizobium meliloti. Science 2001, 293:668-672.

8. Reeve W, Chain P, O'Hara G, Ardley J, Nandesena K, Brau L, Tiwari R, Malfatti S, Kiss H, Lapidus A, Copeland A, Nolan M, Land M, Hauser L, Chang Y-J, Mavromatis K, Markowitz V, Kyrpides NC, Gollagher M, Yates R, Dilworth M, Howieson J: Complete genome sequence of the Medicago microsymbiont Ensifer (Sinorhizobium) medicae strain WSM419. Stand Genomic Sci 2010, 2:77-86.

9. Schmeisser $C$, Liesegang $H$, Krysciak D, Bakkou N, Le Quere A, Wollherr A, Heinemeyer I, Morgenstern B, Pommerening-Roser A, Flores M, Palacios R,

\footnotetext{
Abbreviations Groups; LCO: lipo-chito-oligosaccharide; $\mathrm{N}_{2}$ : dinitrogen; PC: phenotype spectinomycin; T3SS, T4SS, and T6SS: bacterial type III, IV, and VI protein secretion systems, respectively.
} 
Brenner S, Gottschalk G, Schmitz RA, Broughton WJ, Perret X, Strittmatter AW, Streit WR: Rhizobium sp. strain NGR234 possesses a remarkable number of secretion systems. Appl Environ Microbiol 2009, 75:4035-4045

10. Galardini M, Mengoni A, Brilli M, Pini F, Fioravanti A, Lucas S, Lapidus A, Cheng JF, Goodwin L, Pitluck S, Land M, Hauser L, Woyke T, Mikhailova N, Ivanova N, Daligault H, Bruce D, Detter C, Tapia R, Han C, Teshima H, Mocali S, Bazzicalupo M, Biondi EG: Exploring the symbiotic pangenome of the nitrogen-fixing bacterium Sinorhizobium meliloti. BMC Genomics 2011, 12:235.

11. Weidner S, Becker A, Bonilla I, Jaenicke S, Lloret J, Margaret I, Puhler A, RuizSainz JE, Schneiker-Bekel S, Szczepanowski R, Vinardell JM, Zehner S, Göttfert M: Genome sequence of the soybean symbiont Sinorhizobium fredii HH103. J Bacteriol 2012, 194:1617-1618.

12. Tian CF, Zhou YJ, Zhang YM, Li QQ, Zhang YZ, Li DF, Wang S, Wang J, Gilbert LB, Li YR, Chen WX: Comparative genomics of rhizobia nodulating soybean suggests extensive recruitment of lineage-specific genes in adaptations. Proc Natl Acad Sci USA 2012, 109:8629-8634.

13. Bailly X, Giuntini E, Sexton MC, Lower RP, Harrison PW, Kumar N, Young JP. Population genomics of Sinorhizobium medicae based on low-coverage sequencing of sympatric isolates. ISME J 2011, 5:1722-1734.

14. Denarie J, Cullimore J: Lipo-oligosaccharide nodulation factors: a minireview new class of signaling molecules mediating recognition and morphogenesis. Cell 1993, 74:951-954.

15. Leigh JA, Walker GC: Exopolysaccharides of Rhizobium: synthesis, regulation and symbiotic function. Trends Genet 1994, 10:63-67.

16. Breedveld MW, Miller KJ: : Cyclic beta-glucans of members of the family Rhizobiaceae. Microbiol Rev 1994, 58:145-161.

17. Fauvart M, Michiels J: Rhizobial secreted proteins as determinants of host specificity in the rhizobium-legume symbiosis. FEMS Microbiol Lett 2008, 285:1-9.

18. MacLean AM, Finan TM, Sadowsky MJ: Genomes of the symbiotic nitrogen-fixing bacteria of legumes. Plant Physiol 2007, 144:615-622.

19. Amadou C, Pascal G, Mangenot S, Glew M, Bontemps C, Capela D, Carrere S, Cruveiller S, Dossat C, Lajus A, Marchetti M, Poinsot V, Rouy Z, Servin B, Saad M, Schenowitz C, Barbe V, Batut J, Médigue C, MassonBoivin C: Genome sequence of the beta-rhizobium Cupriavidus taiwanensis and comparative genomics of rhizobia. Genome Res 2008, 18:1472-1483

20. Epstein B, Branca A, Mudge J, Bharti AK, Briskine R, Farmer AD, Sugawara M, Young ND, Sadowsky MJ, Tiffin P: Population genomics of the facultatively mutualistic bacteria Sinorhizobium meliloti and S. medicae. PLoS Genet 2012, 8:e1002868

21. Branca A, Paape TD, Zhou P, Briskine R, Farmer AD, Mudge J, Bharti AK, Woodward JE, May GD, Gentzbittel L, Ben C, Denny R, Sadowsky MJ, Ronfort J, Bataillon T, Young ND, Tiffin P: Whole-genome nucleotide diversity, recombination, and linkage disequilibrium in the model legume Medicago truncatula. Proc Natl Acad Sci USA 2011, 108:E864-870.

22. Young ND, Debellé F, Oldroyd GE, Geurts R, Cannon SB, Udvardi MK, Benedito VA, Mayer KF, Gouzy J, Schoof H, Van de Peer Y, Proost S, Cook DR, Meyers BC, Spannagl M, Cheung F, De Mita S, Krishnakumar V, Gundlach H, Zhou S, Mudge J, Bharti AK, Murray JD, Naoumkina MA, Rosen B, Silverstein KA, Tang H, Rombauts S, Zhao PX, Zhou P, et al: The Medicago genome provides insight into the evolution of rhizobial symbioses. Nature 2011, 480:520-524.

23. Sugawara M, Shah GR, Sadowsky MJ, Paliy O, Speck J, Vail AW, Gyaneshwar P: Expression and functional roles of Bradyrhizobium japonicum genes involved in the utilization of inorganic and organic sulfur compounds in free-living and symbiotic conditions. Mol PlantMicrobe Interact 2011, 24:451-457.

24. Autry AR, Fitzgerald JW: Sulfonate-S - a major form of forest soil organic sulfur. Biol Fert Soils 1990, 10:50-56.

25. Giraud $E$, Moulin L, Vallenet $D$, Barbe V, Cytryn E, Avarre JC, Jaubert M, Simon D, Cartieaux F, Prin Y, Bena G, Hannibal L, Fardoux J, Kojadinovic M, Vuillet L, Lajus A, Cruveiller S, Rouy Z, Mangenot S, Segurens B, Dossat C, Franck WL, Chang WS, Saunders E, Bruce D, Richardson P, Normand P, Dreyfus B, Pignol D, Stacey G, Emerich D, Verméglio A, Médigue C, Sadowsky M: Legumes symbioses: absence of Nod genes in photosynthetic bradyrhizobia. Science 2007, 316:1307-1312.

26. Spaink HP, Sheeley DM, van Brussel AA, Glushka J, York WS, Tak T, Geiger O, Kennedy EP, Reinhold VN, Lugtenberg BJ: A novel highly unsaturated fatty acid moiety of lipo-oligosaccharide signals determines host specificity of Rhizobium. Nature 1991, 354:125-130

27. Stacey G, Luka S, Sanjuan J, Banfalvi Z, Nieuwkoop AJ, Chun JY, Forsberg LS, Carlson R: nodZ, a unique host-specific nodulation gene, is involved in the fucosylation of the lipooligosaccharide nodulation signal of Bradyrhizobium japonicum. J Bacteriol 1994, 176:620-633.

28. Lewin A, Cervantes E, Chee-Hoong W, Broughton WJ: nodSU, two new nod genes of the broad host range Rhizobium strain NGR234 encode host-specific nodulation of the tropical tree Leucaena leucocephala. Mol Plant-Microbe Interact 1990, 3:317-326.

29. Jabbouri S, Relic B, Hanin M, Kamalaprija P, Burger U, Prome D, Prome JC, Broughton WJ: nolO and noel (Hsnlll) of Rhizobium sp. NGR234 are involved in 3-O-carbamoylation and 2-0-methylation of Nod factors. J Biol Chem 1998, 273:12047-12055.

30. Lorquin J, Lortet G, Ferro M, Mear N, Dreyfus B, Prome JC, Boivin C: Nod factors from Sinorhizobium saheli and $S$. teranga bv. sesbaniae are both arabinosylated and fucosylated, a structural feature specific to Sesbania rostrata symbionts. Mol Plant-Microbe Interact 1997, 10:879-890.

31. Chen H, Gao K, Kondorosi E, Kondorosi A, Rolfe BG: Functional genomic analysis of global regulator NoIR in Sinorhizobium meliloti. Mol PlantMicrobe Interact 2005, 18:1340-1352.

32. Cren $\mathrm{M}$, Kondorosi $\mathrm{A}$, Kondorosi $\mathrm{E}:$ An insertional point mutation inactivates NolR repressor in Rhizobium meliloti 1021. J Bacteriol 1994, 176:518-519.

33. Tseng $\Pi$, Tyler BM, Setubal JC: Protein secretion systems in bacterial-host associations, and their description in the Gene Ontology. BMC Microbiol 2009, 9(Suppl 1):S2.

34. Lopez-Baena FJ, Vinardell JM, Perez-Montano F, Crespo-Rivas JC, Bellogin RA, Espuny Mdel R, Ollero FJ: Regulation and symbiotic significance of nodulation outer proteins secretion in Sinorhizobium fredii HH103. Microbiol 2008, 154:1825-1836.

35. Viprey V, Del Greco A, Golinowski W, Broughton WJ, Perret X: Symbiotic implications of type III protein secretion machinery in Rhizobium. Mol Microbiol 1998, 28:1381-1389.

36. Cascales E, Christie PJ: The versatile bacterial type IV secretion systems. Nat Rev Microbiol 2003, 1:137-149.

37. Jones KM, Lloret J, Daniele JR, Walker GC: : The type IV secretion system of Sinorhizobium meliloti strain 1021 is required for conjugation but not for intracellular symbiosis. J Bacterio/ 2007, 189:2133-2138.

38. Hubber AM, Sullivan JT, Ronson CW: Symbiosis-induced cascade regulation of the Mesorhizobium loti R7A VirB/D4 type IV secretion system. Mol Plant-Microbe Interact 2007, 20:255-261.

39. Bladergroen MR, Badelt K, Spaink HP: Infection-blocking genes of a symbiotic Rhizobium leguminosarum strain that are involved in temperature-dependent protein secretion. Mol Plant-Microbe Interact 2003, 16:53-64.

40. Mesa S, Gottfert M, Bedmar EJ: The nir, nor, and nos denitrification genes are dispersed over the Bradyrhizobium japonicum chromosome. Arch Microbiol 2001, 176:136-142.

41. Torres MJ, Rubia MI, Bedmar EJ, Delgado MJ: Denitrification in Sinorhizobium meliloti. Biochem Soc Trans 2011, 39:1886-1889.

42. Koch M, Delmotte N, Rehrauer H, Vorholt JA, Pessi G, Hennecke H: Rhizobial adaptation to hosts, a new facet in the legume root-nodule symbiosis. Mol Plant Microbe Interact 2010, 23:784-790.

43. Hummerjohann J, Laudenbach S, Retey J, Leisinger T, Kertesz MA: The sulfur-regulated arylsulfatase gene cluster of Pseudomonas aeruginosa, a new member of the cys regulon. J Bacteriol 2000, 182:2055-2058.

44. Ardourel M, Lortet G, Maillet F, Roche P, Truchet G, Prome JC, Rosenberg C: In Rhizobium meliloti, the operon associated with the nod box $\mathrm{n} 5$ comprises nodL, noeA and noeB, three host-range genes specifically required for the nodulation of particular Medicago species. Mol Microbiol 1995, 17:687-699.

45. van Berkum P, Elia P, Eardly BD: Multilocus sequence typing as an approach for population analysis of Medicago-nodulating rhizobia. J Bacteriol 2006, 188:5570-5577.

46. Heath KD: Intergenomic epistasis and coevolutionary constraint in plants and rhizobia. Evolution 2010, 64:1446-1458.

47. ABySS.. [http://www.bcgsc.ca/platform/ bioinfo/software/abyss/].

48. Bocs $S$, Cruveiller $S$, Vallenet D, Nuel G, Medigue C: AMIGene: Annotation of Microbial Genes. Nucleic Acids Res 2003, 31:3723-3726. 
49. Vallenet D, Engelen S, Mornico D, Cruveiller S, Fleury L, Lajus A, Rouy Z, Roche D, Salvignol G, Scarpelli C, Medigue C: MicroScope: a platform for microbial genome annotation and comparative genomics. Database (Oxford) 2009, 2009:bap021.

50. Becker A, Barnett MJ, Capela D, Dondrup M, Kamp PB, Krol E, Linke B, Rüberg S, Runte K, Schroeder BK, Weidner S, Yurgel SN, Batut J, Long SR, Pühler A, Goesmann A: A portal for rhizobial genomes: RhizoGATE integrates a Sinorhizobium meliloti genome annotation update with postgenome data. J Biotechnol 2009, 140:45-50.

51. MaGe interface.. [https://www.genoscope.cns.fr/agc/microscope/home/ index.php].

52. CD-HIT.. [http://weizhong-lab.ucsd.edu/cd-hit/]

53. Felsenstein J: PHYLIP - Phylogeny Inference Package (Version 3.2). Cladistics 1989, 5:164.

54. Sukumaran J, Holder MT: DendroPy: a Python library for phylogenetic computing. Bioinformatics 2010, 26:1569-1571.

55. Bucciarelli B, Hanan J, Palmquist D, Vance CP: A standardized method for analysis of Medicago truncatula phenotypic development. Plant Physiol 2006, 142:207-219.

56. Sadowsky MJ, Tully RE, Cregan PB, Keyser HH: Genetic diversity in Bradyrhizobium japonicum serogroup 123 and its relation to genotypespecific nodulation of soybean. Appl Environ Microbiol 1987, 53:2624-2630.

57. R 2.14.1.. [http://cran.r-project.org/bin/windows/base/].

58. O'Hara GW, Franklin M, Dilworth MJ: Effect of sulfur supply on sulfate uptake, and alkaline sulfatase activity in free-living and symbiotic bradyrhizobia. Arch Microbiol 1987, 149:163-167. and accessory genomes of 48 Sinorhizobium strains comprising five genospecies. Genome Biology 2013 14:R17.

\section{Submit your next manuscript to BioMed Central and take full advantage of:}

- Convenient online submission

- Thorough peer review

- No space constraints or color figure charges

- Immediate publication on acceptance

- Inclusion in PubMed, CAS, Scopus and Google Scholar

- Research which is freely available for redistribution

Submit your manuscript at www.biomedcentral.com/submit
C Biomed Central 